Document downloaded from:

http://hdl.handle.net/10251/73089

This paper must be cited as:

Díaz Aldana, NL.; Guarnizo Marín, JG.; Mellado Arteche, M.; Vasquez, JC.; Guerrero, JM. (2016). A Robot-Soccer-Coordination Inspired Control Architecture Applied to Islanded Microgrids. IEEE Transactions on Power Electronics. PP(99):1-15.

doi:10.1109/TPEL.2016.2572262.

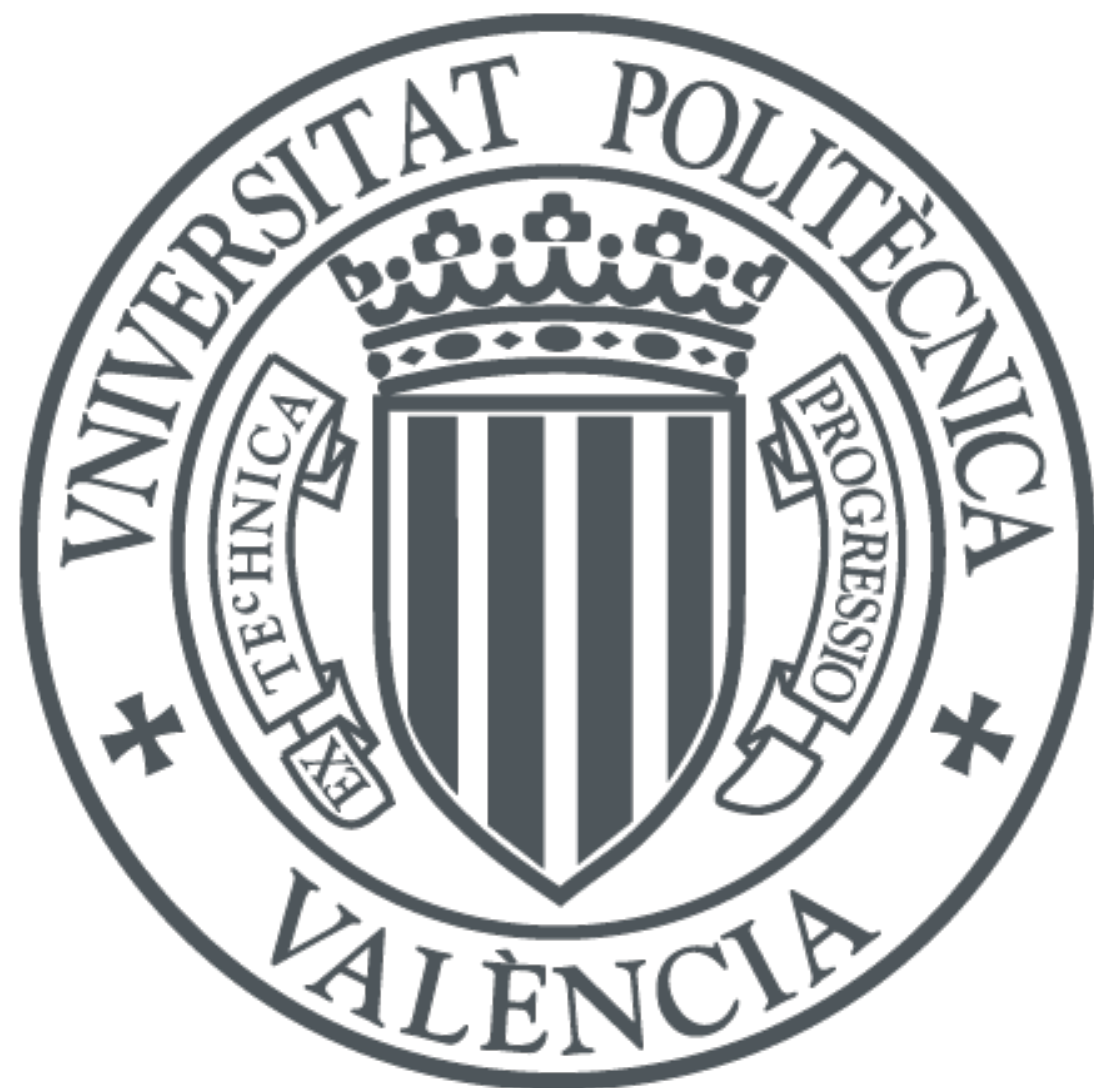

The final publication is available at

http://dx.doi.org/10.1109/TPEL.2016.2572262

Copyright Institute of Electrical and Electronics Engineers (IEEE)

Additional Information

(C) 2016 IEEE. Personal use of this material is permitted. Permission from IEEE must be obtained for all other uses, in any current or future media, including reprinting/republishing this material for advertising or promotional purposes, creating new collective works, for resale or redistribution to servers or lists, or reuse of any copyrighted component of this work in other works. 


\title{
A Robot-Soccer-Coordination Inspired Control Architecture Applied to Islanded Microgrids
}

\author{
Nelson L. Díaz, Student Member, IEEE, \\ José G. Guarnizo, Martin Mellado, Juan C. Vasquez, Senior, IEEE, and Josep M. Guerrero Fellow, IEEE,
}

\begin{abstract}
Nowadays islanded microgrids present a high interest due to the increasing penetration of renewable energy resources, especially in remote areas, or for improving the local energy reliability. A microgrid can operate in gridconnected or islanded mode, being necessary the use of energy storage systems under islanded operation, in order to ensure the generation/consumption power balance and smooth uncertainties in the dynamics of the renewable energy sources. Particularly, in islanded operation at least one of the distributed energy resources should assume the regulation of the common bus. In a microgrid, every distributed energy resource may be able to cooperate with the grid regulation in accordance to its particular operational conditions. In this sense, a centralized unit with a global perception of the load demand, the power provided by the renewable energy sources, and the storage capacity of the energy storage systems, may ensure proper and reliable operation of the microgrid. This paper proposes a structured architecture based on tactics, roles and behaviors for a coordinated operation of islanded microgrids. The architecture is inspired on a robot soccer strategy with global perception and centralized control, which determines the changes among operation modes for the distributed energy resources in an islanded ac microgrid.
\end{abstract}

Index Terms-Keywords: Behaviors, Centralized architecture, Distributed Storage and Generation, Roles, Tactics.

\section{INTRODUCTION}

$\mathbf{N}$ OWADAYS, the integration of distributed generation is gaining more attention due to the increasing penetration of renewable energy sources (RESs) such as photovoltaic (PV) and wind turbine (WT) generation. Also, energy storage systems (ESSs) are commonly used for smoothing the unpredictable behavior of RESs and facilitating their integration to the power grid. In this

N. L. Díaz is with the Department of Energy Technology, Aalborg University, Aalborg 9220, Denmark; and also with the Engineering Faculty, Universidad Distrital F.J.C., Bogotá, Colombia (e-mail: nda@et.aau.dk; nldiaza@udistrital.edu.co).

J. G. Guarnizo is with Instituto de Automática e Informática Industrial, Universitat Politècnica de València. Valencia. Spain and also with Laboratory of Alternative Sources of Energy LIFAE. Universidad Distrital F.J.C., Bogotá, Colombia (e-mail: jguarnizo@correo.udistrital.edu.co)

M. Mellado is with Instituto de Automática e Informática Industrial, Universitat Politècnica de València. Valencia. Spain. (e-mail: martin@ai2.upv.es)

J. C. Vasquez, and J. M.Guerrero are with the Department of Energy Technology, Aalborg University, Aalborg 9220, Denmark (email:juq@et.aau.dk; joz@et.aau.dk).

N. L. Díaz and J. G. Guarnizo were supported by a scholarship from the Administrative Department of Science, Technology and Innovation COLCIENCIAS, Colombia. sense, Microgrids have emerged as a concept for the integration of RESs, ESSs and loads which can operate either, in grid-connected or islanded mode [1]. In grid-connected operation, the utility grid determines the frequency and voltage at the common bus and is responsible of maintaining the power balance between generation and consumption [2]. Meanwhile, the distributed energy resources (DERs) exchange power with the energized grid [3], [4].

On the other hand, the problem of managing the power balance is more challenging on islanded microgrids, since it is required that at least one of the DERs assumes the grid-forming role, becoming responsible of setting the voltage amplitude and frequency of the local grid [4], [5]. In particular, two main approaches have been used for local grid regulation in islanded systems: Single-Master (one unit in grid-forming operation) or Multi-Master (several parallel connected units operating in grid-forming role) [3]. In Multi-Master approach, the power balance is shared among parallel connected gridforming units [4].

For a reliable operation of islanded microgrids, it is important to define adequate control architectures which coordinates the operation of the DERs. The control architecture should define the units responsible of the grid-forming role by considering several factors such as the load demand, the available power from RESs and the storage capacity of ESSs [1]. In fact, the state of charge $(\mathrm{SoC})$ of the ESSs is probably the main issue to consider when the control architecture is defined. To be more precise, it is absolutely important avoiding depthdischarge and overcharge of the ESSs for preserving the lifespan of the ESSs, especially when they are based on batteries [6]. Typically, bank of batteries are the most used for the deployment of ESSs in islanded systems, since they offer a good commitment between lifetime, transportability, availability and cost [7], [8].

Different centralized architectures have been proposed, in which the power generation of the DERs is scheduled to maintain an appropriate level of charge at the ESSs, while ensuring the power balance in the microgrid [9], [10]. Normally, the ESSs are the units who assume the grid-forming role, while RESs supply power to the islanded microgrid [3], [11]. For instance, in [12] and [13] the power generation from RESs is curtailed in order to keep the stored energy within desired levels, and ensuring the power balance in the microgrid. Other 
approaches, have considered the operation of the ESSs as voltage sources which follow adaptive power-frequency characteristics curves, in this way the power is scheduled in accordance to the SoC [1], [2], [14]. The main drawback of these approaches is that larger frequency deviations are required for ensuring coordination of the DERs, even in steady state. For that reason, secondary frequency restoration cannot be applied in those approaches [11].

Proper charging of ESSs based on batteries is critically important to improve their lifespan and performance. The best way of charging ESSs based on batteries is by means of a two stage procedure: current-limited charge followed by a constant-voltage charge. In the constant-voltage charge, the battery voltage should be kept constant, while the battery current begins to taper and the battery approaches to its state of full charge [7]. The constant-voltage charge requires a current controlled operation. This fact, implies that the ESSs must change its control operation mode. Then, the operation of the others DERs should be coordinated in order to ensure that at least one of them assumes the regulation of the common bus. In this sense, a distributed coordination strategy, which considers the different stages for charging properly ESSs, has been previously proposed in [15]. In this work, voltage and frequency bus-signalling is used to trigger the changes at the operation modes for all the DERs. Despite the approach in [15] has proved to be effective, any perturbation or noises in the power line could cause unexpected changes in the operation modes, which may lead the microgrid to an unexpected operation. On top of that, because of the distributed nature of the approach proposed in [15], frequency and voltage restoration cannot be achieved, since voltage and frequency deviations are required for triggering the changes. Moreover, multi-agent architectures have emerged as an alternative in order to coordinate the changes at the control operation mode.

Recently, works based on multi-agent systems are becoming more used in different domains, including applications for microgrids, where many agents work together in complex systems towards a common goal. For instance, in [16] it is proposed an optimal strategy for integration and arbitration of conflicting interests between producer/consumer agents in a smart energy grid. In [17] authors propose an architecture based on multi-agent systems for smart grid management and forecasting. Also, an agent based algorithm is presented in [18] for service restoration with distributed energy storage. Multi-agent systems have been also used as optimization algorithm in Smart Grids grids [19]. Particularly in [20], smart microgrids have been modelled as a team of cooperative agents, where each microgrid can exchange power with other microgrids and the main grid. In [21], it is proposed the IEC/ISO 62264 standard for adapting the hierarchical control and energy storage in microgrids in different applications based on multiagent systems, such as market participation and control in virtual power plants.

Particularly, multi-agent approaches have been applied to islanded microgrids, for cooperative and coordinated operation between distributed units, by means of multi-layer control structures. The agents, defined in intermediate control layers, ensure the common bus regulation by using deliberative agreements between them [22]-[24].

Moreover, multi-agents have been successfully used to solve coordination problems in other engineering fields. For instance robot soccer is a multi-agent system, which includes uncertainties and hostile environment, where robots work coordinated on a real challenging problem [25]. Coordination is important in order to obtain a better team performance in a game, by playing with collaborative behaviors. In contrast, lack of coordination can lead to system failures [26]. In robot soccer approach, strategy can be described as the plan of the robot soccer team, expecting to win a game, while tactic is referred to the organization of the team for the game [27]. In [28], role is defined as a list of behaviors for the robot to perform in sequence and they are usually allocated in a dynamical way [29]. Behaviors are the basic sensorimotor skills of the robot, like moving to a specific position or kicking the ball [30].

This paper proposes a structured control architecture inspired on a centralized robot soccer strategy based on tactics, roles and behaviors presented in [31], but adapted for a coordinated operation of an islanded ac microgrid. The proposed strategy is deployed in a centralized control unit with global perception of the operational conditions of the microgrid. The centralized coordination defines the adequate allocation of roles and behaviors for all the DERs in order to ensure the common bus regulation and reliable operation of the microgrid under different operational conditions by means of a hierarchical finite state machine. The proposed tactics allow, among other objectives, the equalization of the SoC for distributed ESSs, load shedding and power curtailment of RESs generation when is required. Additionally, the proposed strategy considers proper stages for charging ESSs based on batteries. The main advantage of the proposed model is to provide a holistic system architecture with a knowledge based role assignation. This approach allows an intuitive specification for a multi-agent model, starting out with the conceptual design phase and facilitating cross-domain development in a complex environment, which has proved its effectiveness in a robot soccer environment. Given the above, this architecture proposed a novel model where the hardware components of a microgrid are presented as hardware agents, where using a robot soccer metaphor the agents are coordinated in order to ensure the adequate operation mode of the ac microgrid, showing also collaborative behaviors among the agents.

In this paper, Section II defines the islanded microgrid model, Section III explains the control architecture, Section IV details the experimental setup used to validate 


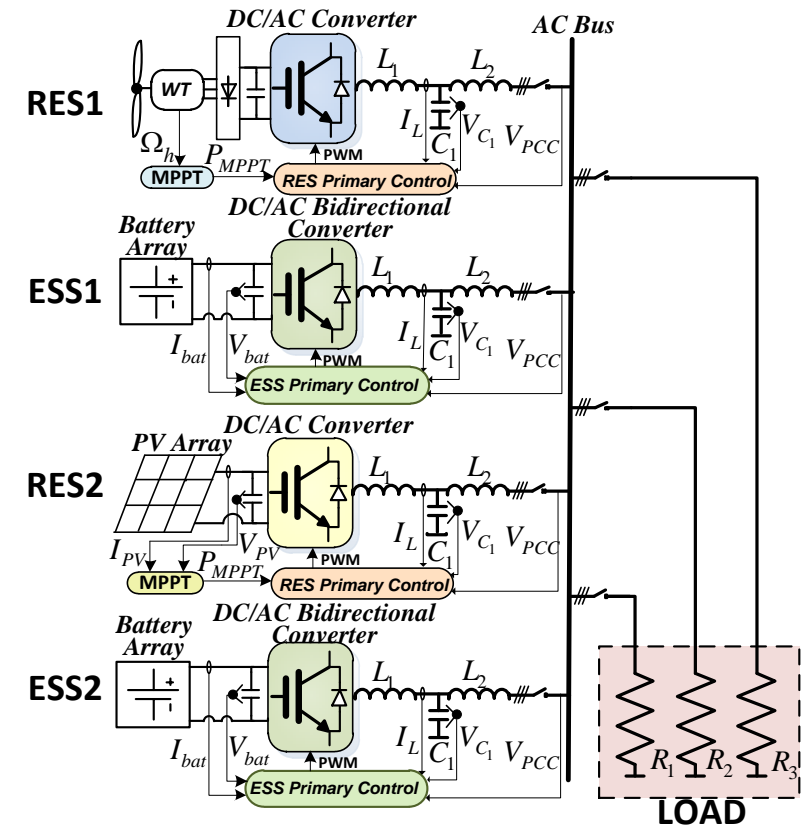

Fig. 1: Islanded Microgrid Configuration

the proposed control architecture, Section V presents and discuses experimental results, and Section VI summarizes the main conclusion of the proposed approach.

\section{MicROGRID MOdEL}

An islanded three-phase ac microgrid based on two RESs (PV and WT generators), critical and non-critical loads, and distributed ESSs based on battery as shown in Fig. 1 will be considered in this study case for evaluating the proposed architecture. Each DER is complemented with a power conversion stage, output filters and primary controllers which are independent local controllers that allow autonomous operation and parallel connection of each unit to the common bus [5], [32].

The current trend in ESSs is oriented to the integration of distributed ESSs instead of a centralized one. In this way, each storage unit can be optimized and configured for the integration of distributed RESs with different characteristics [33]-[35]. Additionally, distributed approach makes easier to retrofit systems that already include ESSs [36]. On top of that, in islanded microgrid applications, the ESSs is mainly based on batteries, particularly lead-acid batteries are the most used [7], [37], [38]. Valve regulated Lead-acid (VRLA) battery arrays will be considered in this study case microgrid.

\section{A. ESSs operation}

For normal operation of the islanded microgrid, it is required that at least one of the DERs (ESSs or RESs) assumes the grid-forming role. Typically, the ESSs assume the grid-forming role, while RESs operate as gridfollowing units by supplying the power defined by their MPPT algorithms to the local grid. In this case, the ESSs are charged or discharged to ensure the power balance

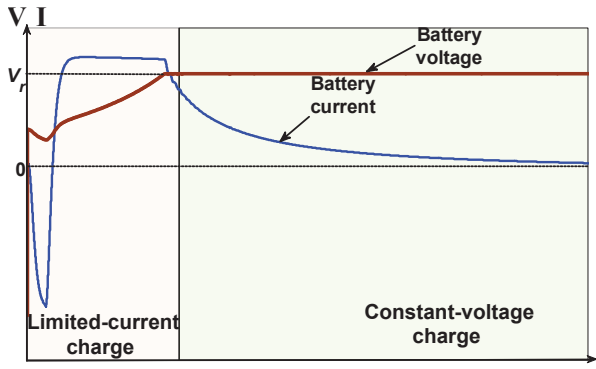

Fig. 2: General Battery Charge Profile

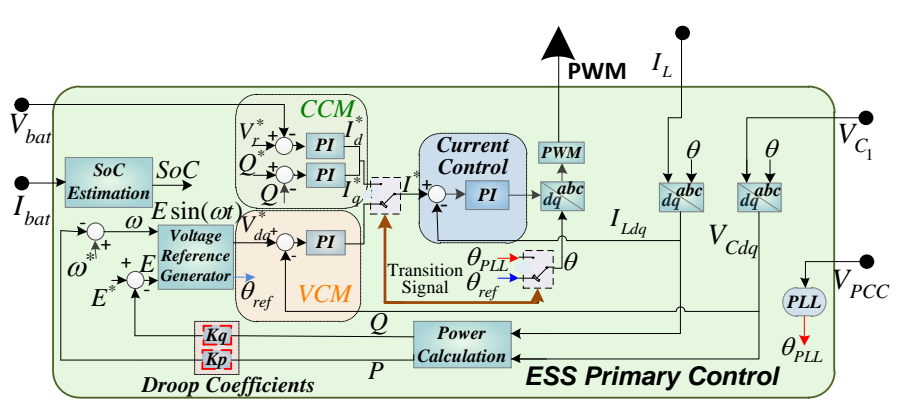

Fig. 3: Control Diagram of the ESSs

in the microgrid. However, for ESSs based on batteries, it is absolutely recommended, by manufactures, to charge completely the batteries between discharge cycles and avoid excessive overcharge. Because of this, a two stage charge procedure which involves a limited-current charge followed by a constant-voltage charge as is shown in Fig. 2, is highly recommended [7].

In the first stage the battery is charged based on the power unbalance between generation and consumption. During this stage, the ESSs are grid-forming units which operates in voltage control mode (VCM). When there is enough energy available from the generation of RESs, the battery array will be charged until its battery voltage $\left(V_{b a t}\right)$ reaches a threshold value commonly known as the regulation voltage $(V r)$ (typically $2.45 \pm 0.05$ volts/cell). Once the regulation value has been reached, this value should be kept constant. This means, that the battery current should start to be reduced in a controlled way in order to keep the battery voltage in a constant value as can be seen in Fig. 2 [7]. At this point, the battery array enters in the second stage for charge (constantvoltage charge). As consequence, the corresponding ESS needs to change its control operation mode from VCM to current control mode (CCM) assuming the role of gridfollowing units. Fig. 3 shows the control scheme for the ESSs. In this figure, it is possible to see that the reference for the inner current controller $\left(I^{*}\right)$ is determined by the control operation mode of the ESSs (VCM or CCM).

\section{B. RESs operation}

In the case of RESs, it is expected to obtain from them the maximum amount of available energy. This can be achieved by means of MPPT strategies which define 


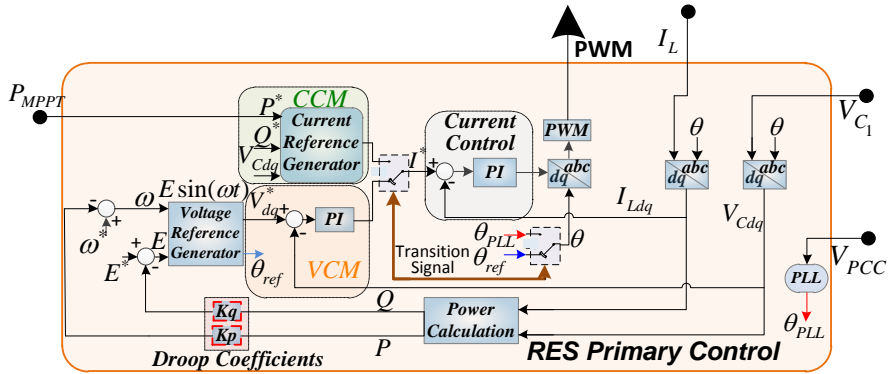

Fig. 4: Control Diagram of the RESs

the power references for primary controllers. Because of this, RESs assume the grid-following role, in which they operates in current control mode (CCM). However, for periods of high generation, all the distributed ESSs may become completely charged. Under this condition, all DERs will operate in CCM as grid-following units, as a consequence the regulation of the common bus will be lost. Regarding that, it is required that at least one of the DERs assumes the regulation of the common bus and taking into account that ESSs are under constant-voltage charge, it is not possible for them to continue with the voltage and frequency regulation. Because of that, one possible solution is to assign the regulation of the common bus to the RESs. In this case, the RESs assume the grid-forming role by changing their control loops from CCM to VCM. Under this condition the power generation from RESs needs to be curtailed in order to keep the balance between generation and consumption and ensures the stability of the common bus [39]. Fig. 4 shows the primary control scheme for RESs. It is possible to see, that the main difference with the primary controller of the ESSs is the definition of the current reference for the current controller. This fact allows a unified and simple design of primary controllers for DERs.

Conventionally, parallel connected grid-forming units use droop control loops in order to share power among them as can be seen in Figs. 3 and 4 [4]. The droop control loops are based on conventional $(P-\omega)$ and $(Q-E)$ functions defined as:

$$
\begin{aligned}
& \omega=\omega^{*}-K_{p} \cdot P_{\text {uniti }} \\
& E=E^{*}-K_{q} \cdot Q_{\text {uniti }}
\end{aligned}
$$

where, $E$ is the voltage amplitude in the output capacitor $C_{1}$ at each inverter. This value, corresponds to the d-component of the capacitor voltage $\left(V_{c d q}\right)$ at each grid-forming unit. The d-axis is considered aligned to the bus voltage for all the units then, in steady state $\left(V_{c d q}=E+j 0\right)$. In addition, $P_{\text {uniti }}$ and $Q_{\text {uniti }}$ are the active and reactive power at the $\mathrm{i}$-th unit in the gridforming role, $E^{*}$ is the inverter output voltage reference, $\omega$ is the angular frequency of the output voltage, $\omega^{*}$ is the reference of the angular frequency, and $K_{p}$ and $K_{q}$ are the droop coefficients [40].

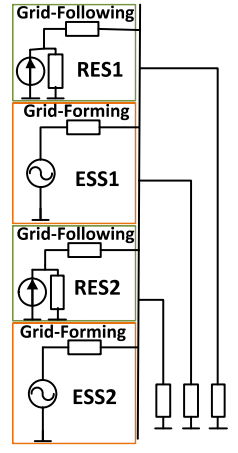

(a)

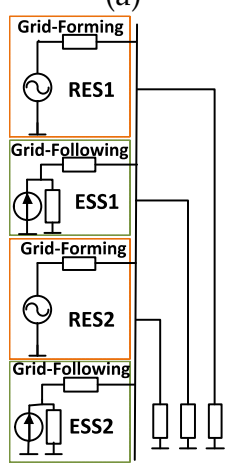

(d)

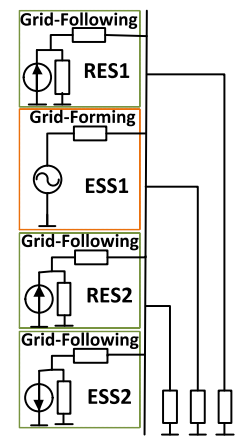

(b)

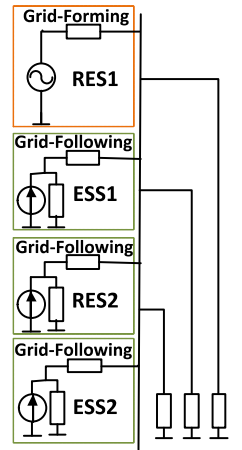

(e)

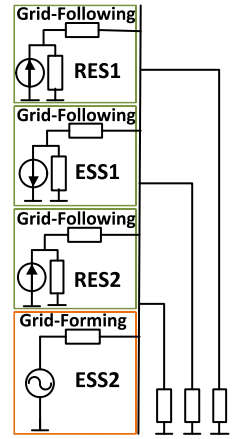

(c)

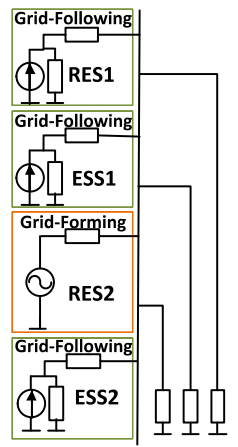

(f)
Fig. 5: Topological operation of the islanded microgrid.

\section{Islanded Microgrid Operation}

As exposed before, for a reliable operation of the islanded microgrid transitions between operation modes has been defined for DERs. Because of this, different topological operation modes can be identified for the microgrid where, it is ensured that at least one of the DERs assumes the grid-forming role. To illustrate, Fig. 5 presents six different topological operations of the microgrid in which the grid-forming role is alternated between ESSs and RESs.

In Fig. 5, the units in the grid-forming role are represented with a voltage source in series whit an output impedance, this is applicable for RESs and ESSs because of the use of unified primary controller. On the other hand, the units in the grid-following role are represented by constant power sources in the case of RESs and constant power loads in the case of ESSs.

In light of the above, it is required a coordinated control architecture which generates the transition signal between roles for each DERs by considering particular operational conditions of each unit and the overall operation of the microgrid. The proposed architecture should also consider load-shedding, or actions for limiting the deep of discharge of the batteries when there is not enough energy available to supply the load demand [11], [41]. In this case, the end-of discharge voltage or low voltage disconnection (LVD) voltage will be considered for load disconnection. The value of the LVD is commonly suggested by the battery manufactures [7]. 


\section{Centralized ARChitecture BAsed ON TACTICS, ROLE AND BEHAVIORS}

As was mentioned before, in robot soccer, the strategy is defined as the plan of the robot soccer team for winning the game, which involves the assignment of roles, formation of players and selection of behaviors. The strategy can be divided in tactics, which correspond to the team organization for a specific game condition, for example the time, the score of the match, the ball locations, or any other specific game situations such as corner kick, by taking into account that only one tactic is selected in each time. To be more clear, the roles for a player are selected based on individual location on the field, actions and behaviors selection. The behaviors are selected based on specific skills of the robots, such as movement, kicking the ball or finding the goal. Particularly, centralized architectures have been widely deployed for coordinated operation of multiagent frameworks such as robot soccer matches [31]. In this scenario, a centralized supervision (emulating a coach) ensures the best vision of the system and agents conditions (state of players in the field). Then, based on the global information adequate tactic is selected, and the roles and behaviors for all the agents can be assigned. In a centralized robot soccer architecture, one centralized decision maker with global perception and global control selects the tactic, assigns roles and selects behaviors to the players from a central computer. In a robot soccer strategy, the players are considered as agents.

In the proposed multi-agent strategy for a coordinated operation of an islanded ac microgrid, all ESSs, RESs and the aggregated load are considered as agents with specific goals and functions defined by the centralized supervision. For the metaphor between robot soccer team coordination, and the coordinated operation of DERs in an islanded microgrid, the strategy is the plan of the microgrid for the common bus regulation while proper levels of charge for the ESSs are ensured. The team is composed by players, in this case they correspond to the distributed ESSs, RESs and the aggregated load. The tactic consists on the organization for the team, depending on the state of charge of the ESSs and RESs generation. Roles correspond to list of behaviors for the players to perform depending on the tactic selected, in order to maintain the plan of the team. In turn, behaviors correspond to basic actions of the players in order to respond to the control actions required, the control behavior corresponds to low level control skills (primary controllers). The formal specification of the robot soccer strategy which inspired this proposed strategy is extensively presented in [31], where the strategy was implemented in a centralized robot soccer league in for a team of 5 two wheeled robots. Fig. 6 presents the overall architecture for the selection of the operation mode in an islanded microgrid using a centralized architecture.

In this case, the operation mode is selected by using a decision maker, programmed in the central computer,

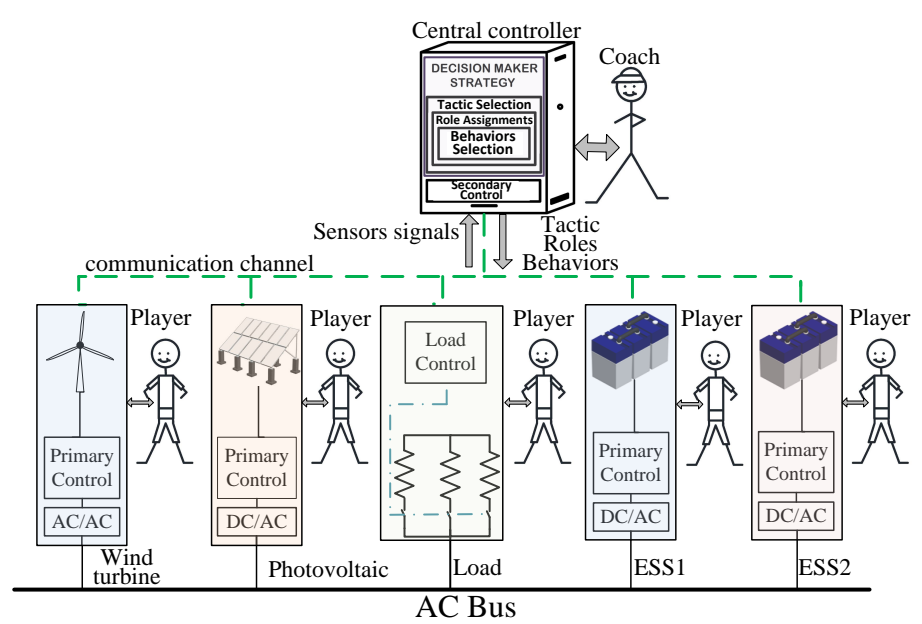

Fig. 6: Overall control architecture

with global perception of the current operational conditions of the microgrid, emulating the virtual coach in the robot soccer environment. In the robot soccer the coach selects the tactic, roles and behaviors depending on game conditions. Similarly, in the microgrid study case, the decision maker uses the sensed signals from the DERs and the Load in order to have a global perception of the operational condition of the microgrid and determine the roles and behaviors of the distributed agents. The decisions from the central unit are transmitted to the agents (RESs, ESSs and the aggregated Load).

The coordination strategy is implemented using a centralized hierarchical finite state machine, as a decision maker, which selects the tactic based on the current operational conditions of the microgrid, and on the status signals of the distributed agents. Once the tactic is selected, a second level finite state machine assigns the roles depending on the tactic previously selected. Next, when roles were assigned, the lowest level finite state machine selects the appropriate behavior for each DERs, in accordance to the role selected. To be more precise, every transition between tactics, roles and behaviors are determined in the central control. The architecture of the coordinated strategy for the operation of the microgrid is presented in Fig. 7.

\section{A. Tactic selection}

As can be seen in Fig. 8, the microgrid operation strategy is defined in three tactics which are selected based on the different islanded microgrid operational conditions. These tactics are: Power balance, activated when the ESSs are charged/discharged in order to ensure the power balance between generation and consumption. Power Curtailment, activated when the ESSs are almost fully charged and the power generated from RESs needs to be adjusted in order to ensure power balance and avoid over-charge of the ESSs. And Load shedding, activated when batteries reach the LVD in order to prevent deeper discharge of the ESSs. This selection takes place in the first level of the hierarchical finite state machine. 


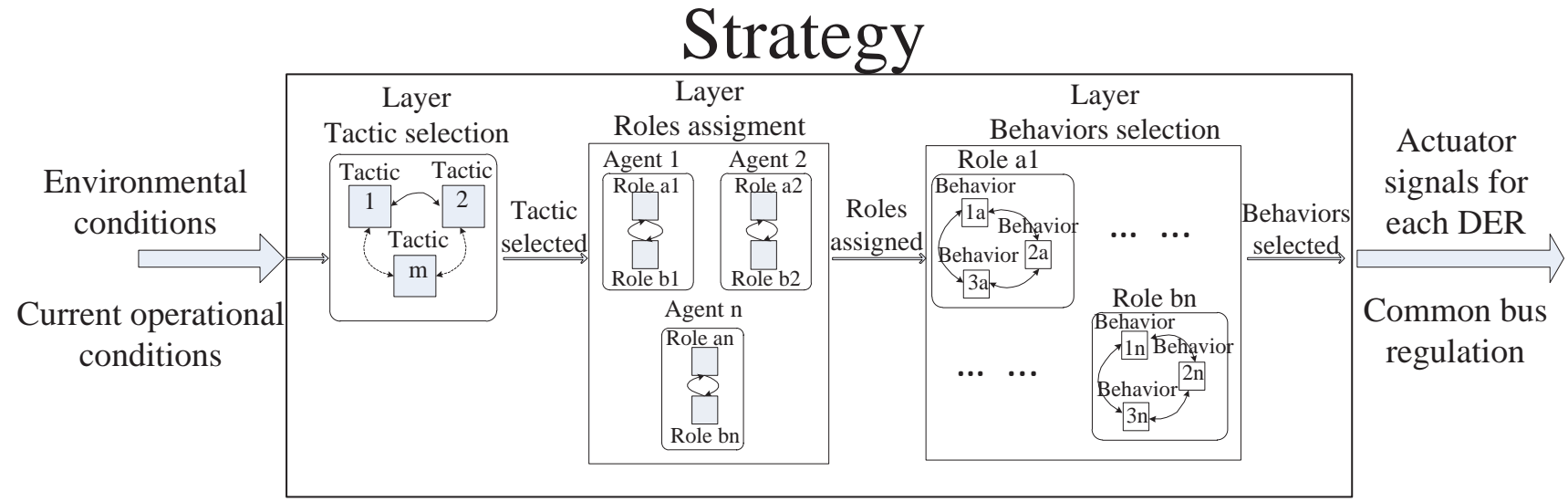

Fig. 7: Architecture of the strategy for coordinated operation of the microgrid.

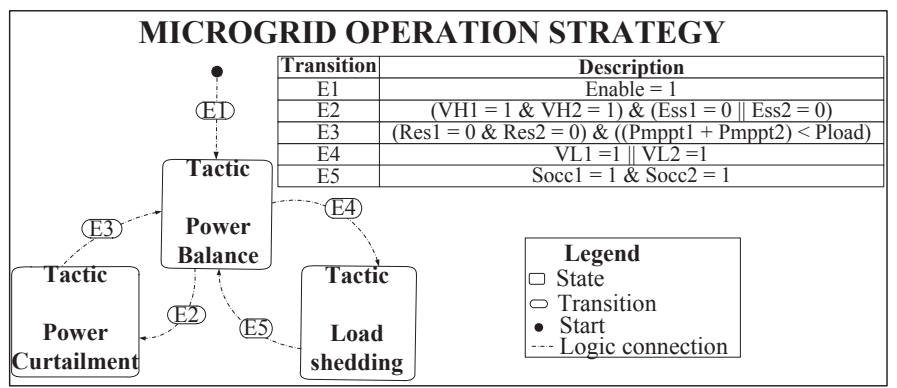

Fig. 8: Tactic selection layer.

In this level, the states correspond to the tactics, and the transitions are defined based on particular operational conditions of the DERs as can be seen in Fig. 8.

From Fig. 8, the transition $E 1$ is a (enable) signal which activates the strategy once the microgrid is turned on and the system is in steady state and stabilized. In the transition E2, $V H 1$ and $V H 2$ correspond to signals that are activated when the battery voltage of the ESS1 and ESS2 respectively, reach the regulation value $V_{r}$. Ess 1 and Ess2 indicate the role of each distributed ESS, being 0 when the ESS is in the grid-following role, and 1 when the ESS is in the grid-forming role. In the transition E3, Res 1 and Res2 indicate the role for each i-th RES unit (grid-following $($ Resi $=0)$ ), or (grid-forming $(\operatorname{Resi}=1)$ ). $P_{M P P T}(R E S 1)$ and $P_{M P P T}(R E S 2)$ correspond to the maximum power value, given by the MPPT strategy, of each RES, and $P_{\text {load }}$ corresponds to the load consumption. For the transition E4,VL1 and VL2 are status signals which are set equal to 1 once their corresponding battery array, reaches a particular low voltage disconnection (LVD) value. For the transition E5, Socc1 and Socc 2 correspond to status signals that are activated $($ Socci $=1)$ when the SoC at the i-th distributed ESSs is bigger than or equal to $60 \%$.

To summarize, two roles have been considered for RESs and ESSs. The first one is grid-forming, which is assigned to the agents responsible of the bus regulation. The second one is grid-following, which is assigned to the agents controlled as current sources. The load maintains a constant role (full-load) when the active tactic is
Power Balance or Power Curtailment. In addition, the load assumes another role (load-adjustment) when the tactic Load Shedding is activated.

\section{B. Tactic Power Balance}

In the second layer of the hierarchical finite state machine, the role assignment is executed depending on the tactic selected in the first layer, and the operational conditions of the microgrid. Fig. 9 shows the role selection and defines the transition signals for the Power Balance tactic. For this tactic, both RESs maintain a constant role (grid-following), generating the maximum amount of available energy. Also the Load has a fixed role (full-load). Both ESSs start with the grid-forming role and the power balance is shared between them by means of droop control loops. When the transitions St01 and St12 are activated, ESS1 and ESS2 change their role to grid-following respectively, this happens when the batteries reach the regulation voltage $\left(V_{b a t i}=V_{r}\right)$.

$$
V H i= \begin{cases}1, & \text { When } V_{b a t i} \geq V_{r} ; \\ 0, & \text { Otherwise }\end{cases}
$$

Indeed, both ESSs can return to the grid-forming role when transitions St10 and St21 are activated. Those events occur when one of the ESSs is still in the gridforming role and the other is in the grid-following role, as is shown in Figs. 5b, and 5c. At this point, the ESS in the grid-forming role starts to be discharged $\left(\operatorname{Sign}\left(P_{\text {bati }}=1\right)\right)$. Consequently, the ESS in the gridfollowing role re-assume the gid-forming role in order to share the power balance responsibility with the other ESS. This response can be considered as a role coordination between agents, such as in the robot soccer environment, where one of the players in the role of attacker should assume the role of defender in order to give support to the team strategy when is required. In the role coordination, operational conditions of the whole system are considered in order to trigger changes in the roles for the different agents.

Apart from that, cooperative behavior such as SoC equalization between distributed ESSs can be defined 
Tactic Power Balance

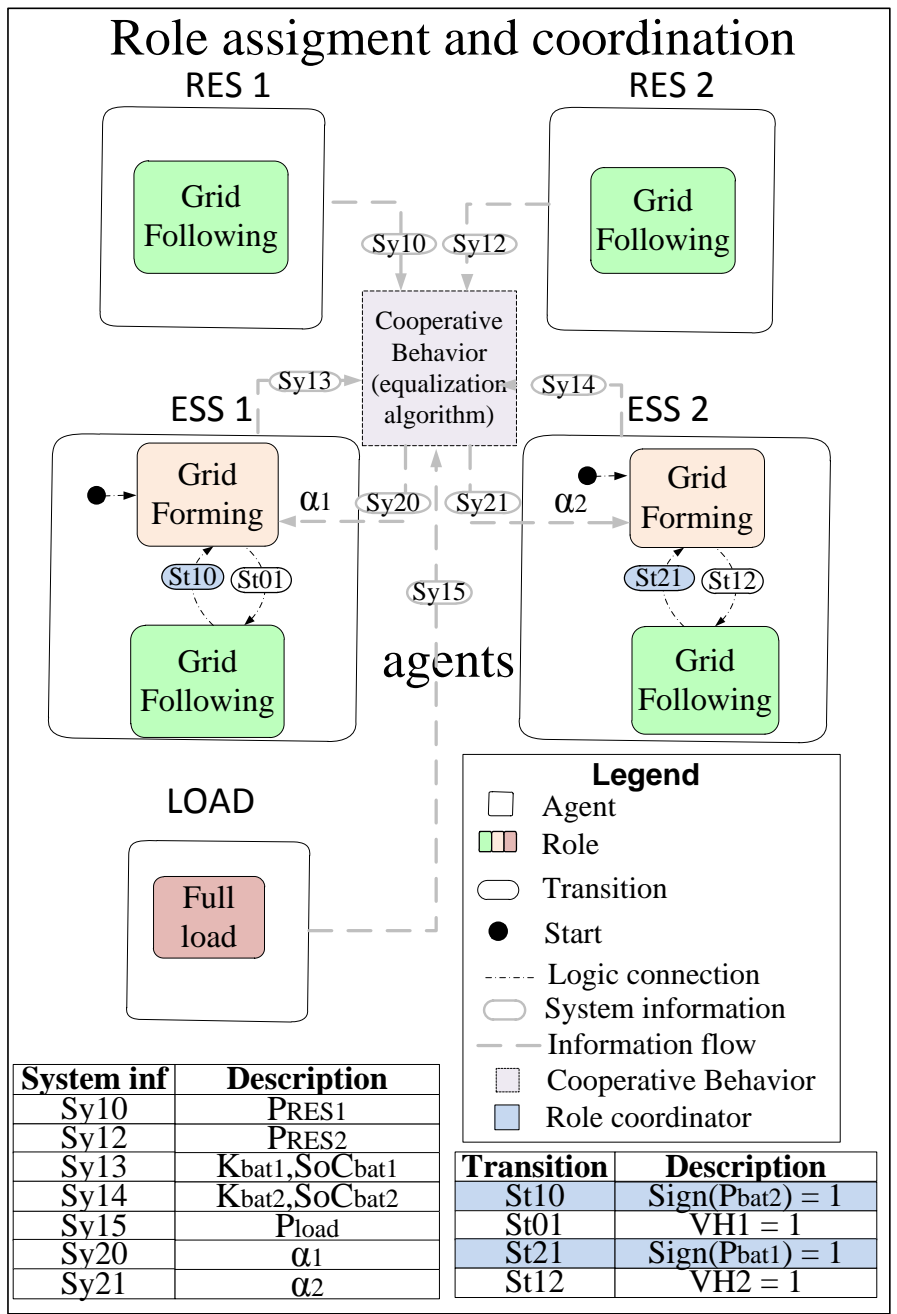

Fig. 9: Role selection and coordination in the tactic Power Balance.

in this tactic. The main idea behind this, is that the ESS with more stored energy contributes with more power to the system, and the ESS with the smallest amount of stored energy is charged faster than the others during periods of battery charging. This process of SoC equalization adds several advantages to the operation of the migrogrid such as reduction of the deep of discharge over all the distributed storage units, faster charge of all the distributed ESSs -what is critically important to the lifespan and performance of ESSs based on batteries- and smooth transition between operation modes [42]. In analogy with a robot soccer match, in the case of two agents in the role of defenders, the defender with the nearest distance to the opponent with the ball possession goes directly to intercept that opponent. At the same time, the other defender goes to obstruct another opponent in order to intercept possible passes or just avoid a free motion of the opponent [31].

In this application, an equalization algorithm, as proposed in [43] and [44], is consider as a cooperative behavior for the equalization of the SoC between distributed ESSs. The equalization programme is summarized in the Algorithm 1. The equalization algorithm requires information from all the agents in the system as is shown in Fig. 9. Where, Sy10 and Sy12 correspond to the current power generation from RES1 $\left(P_{R E S 1}\right)$ and RES2 $\left(P_{\text {RES2 }}\right)$ respectively, $S y 15$ is the load consumption $\left(P_{\text {load }}\right), S y 13$ and Sy14 contain specific information about each ESS summarized in the parameter $K_{b a t i}$, which is as:

$$
K_{b a t i} \approx\left(\frac{V_{b a t i} C_{b a t i}}{\eta_{b a t i}}\right)
$$

where, $V_{\text {bati }}$ is the voltage of the i-th battery array, $C_{\text {bati }}$ is the capacity in $(\mathrm{A} / \mathrm{h})$ and $\eta_{b a t i}$ is the charging/discharging efficiency, and the SoC of each battery which is estimated based on the well known amperehour (Ah) counting method defined as:

$$
\operatorname{SoC}(\Delta t)_{b a t i}=\operatorname{SoC}(0)_{b a t i}-\int_{0}^{\Delta t} \eta_{b a t i} \frac{I_{b a t i}(\tau)}{C_{b a t i}} d \tau
$$

where, $\operatorname{SoC}(0)_{b a t i}$ is the initial SoC, and $I_{b a t i}(\tau)$ is the instantaneous current at each battery array [7].

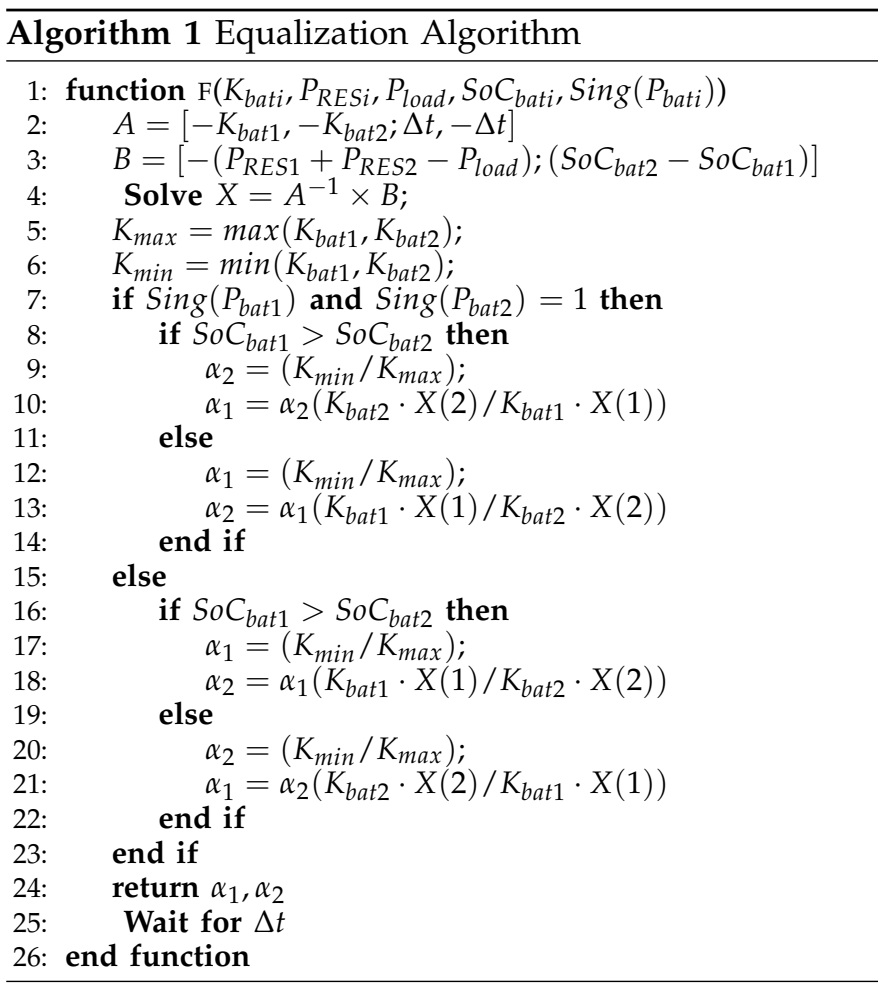

The output of the equalization algorithm are the signals Sy20 and Sy21 which are the weighting factors $\alpha_{1}$ and $\alpha_{2}$ respectively. These factors are used for weighting the droop coefficient $K_{p}$ of the primary droop control loop at each ESS (see Fig. 2). As a consequence, the active power shared between parallel connected ESSs is adjusted in accordance to the SoC of each unit for equalization purpose. Then, the $(P-\omega)$ droop equation described in (1) is modified as:

$$
\omega=\omega^{*}-\alpha_{i} \cdot K_{p} \cdot P_{b a t i}
$$

where, $\left(P_{\text {bati }}\right)$ is the power measured at the i-th ESS. The equalization algorithm is executed during fixed periods $(\Delta t)$ and it is repeated during the whole operation of the 


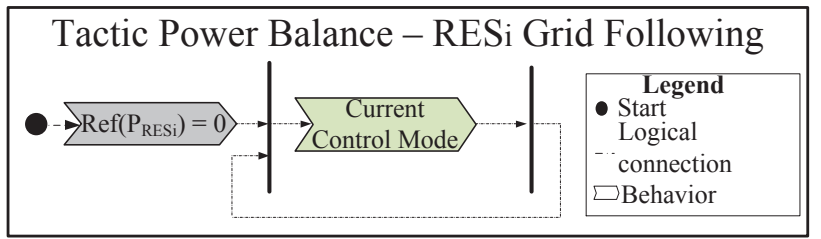

Fig. 10: Behaviors of the RESs in the grid-following role, tactic power balance.

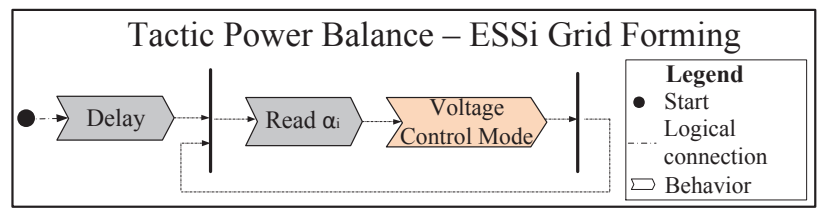

Fig. 11: Behaviors of the ESS in the grid-forming role, tactic power balance.

system. The time for equalization $(\Delta t)$ should be selected regarding maximum power ratings of ESSs.

To get back to the strategy, the behaviors for each agent are assigned in the last layer of the hierarchical finite state machine in accordance to the tactic and the role selected in the previous layers. Specifically, in the tactic Power Balance, it is expected that the RESs follow the power reference $\left(P^{*}\right)$ given by the MPPT algorithm. However, other behaviors can be considered within the operation of the microgrid in which the power reference $P^{*}$ can be scheduled externally by the central controller, in order to curtail the power generation and ensure the power balance in the microgrid. For that reason, a status signal $\left(\operatorname{Re} f\left(P_{R E S i}\right)\right)$ has been defined for setting different references at the RESs controllers in accordance to

$$
P^{*}= \begin{cases}P_{M P P T}(R E S i), & \text { When } \operatorname{Ref}\left(P_{\text {RESi }}\right)=0 ; \\ P_{\text {ext }} i, & \text { When } \operatorname{Ref}\left(P_{\text {RESi }}\right)=1 .\end{cases}
$$

where, $P_{\text {ext }}$ is the power reference scheduled externally. This value will be explained in the next subsection. The behavior of RESs in the grid-following role during the tactic Power Balance is shown in Fig. 10 where, the RESs activate the CCM operation.

The behavior activated for the ESSs during the tactic Power Balance in the grid-forming role is shown in Fig. 11. In the first step, there is a delay which is added intentionally in order to overcome the effect of transitory responses such as system start-up and circulating currents which may appear when there is a transition from CCM to VCM operation. Subsequently, The i-th ESS reads its corresponding factor $\alpha_{i}$ derived from the equalization algorithm, and the VCM is activated.

Fig. 12 presents the behavior for ESSs in the gridfollowing role, during the tactic Power Balance. In this case there is only one behavior activated, which corresponds to the CCM operation.

A similar case is presented with the load agent in the full-load role. During the tactic Power Balance, the full load is connected to the common bus. In this im-

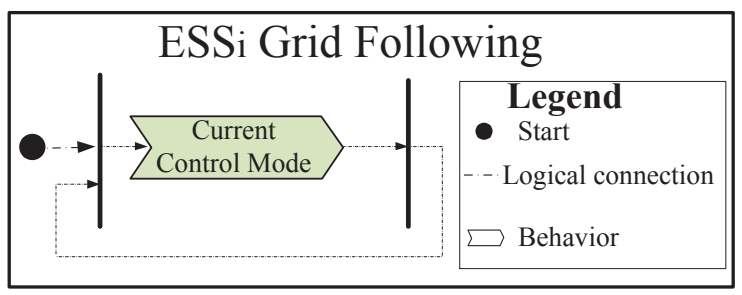

Fig. 12: Behaviors of the ESS in the grid-following role, tactic power balance.

plementation, the full load is composed of three loads connected in parallel, including two non-critical loads, and one critical load which will be disconnected as the last option to prevent further battery discharge.

\section{Tactic Power Curtailment}

Here, ESSs are under constant-voltage charge (gridfollowing operation), where they draws as much power as needed in order to keep their battery array voltage in a constant value $\left(V_{b a t i}=V_{r}\right)$. The fact that the ESSs have reached the second charge stage means that RESs have more energy available than the current power consumption. Therefore, RESs are able to assume the responsibility of the common bus regulation. Fig. 13 shows the role selection layer for the tactic Power Curtailment. Unlike the previous tactic, RESs perform changes in their roles, while the ESSs have a constant role (grid-following) and the load maintains its constant role (Full-Load). Therefore, the microgrid can operate under any of the topological configuration shown in Figs. 5d, $5 e$ and $5 f$.

Starting with grid-forming role, once transitions St13 or $S t 23$ are activated, RES1 or RES2 moves to the role of grid-following respectively. This happens when the maximum power that a RES unit can supply has dropped to any value below the current shared power $\left(P_{R E S i}\right)$. To be more precise, the status signal $C_{M P P T}(R E S i)$ which determines the transitions is defined as:

$C_{M P P T}(R E S i)= \begin{cases}1, & \text { When } P_{M P P T}(R E S i)<P_{R E S i} \\ 0, & \text { When } P_{M P P T}(R E S i) \geq P_{R E S i} .\end{cases}$

Once one RES unit moves to the grid-following role, its power reference $P^{*}$ is initially defined by the MPPT algorithm $\left(\left(\operatorname{Ref}\left(P_{R E S i}\right)=0\right)\right.$ as was presented in $\left.(7)\right)$, since its maximum power generation has fallen. Nevertheless, it is possible that the maximum available power, injected by the RES unit operating in the grid-following role, will increases again. In this case, the idea is to start to share equally the power consumption (half of the energy consumption) with the other RES unit (operating in the role of grid-forming), when the available energy from the RES in the grid-following role is bigger than or equal the maximum available energy in the gridforming unit. Namely, when $\left(P_{M P P T}(\right.$ grid - following $) \geq$ 


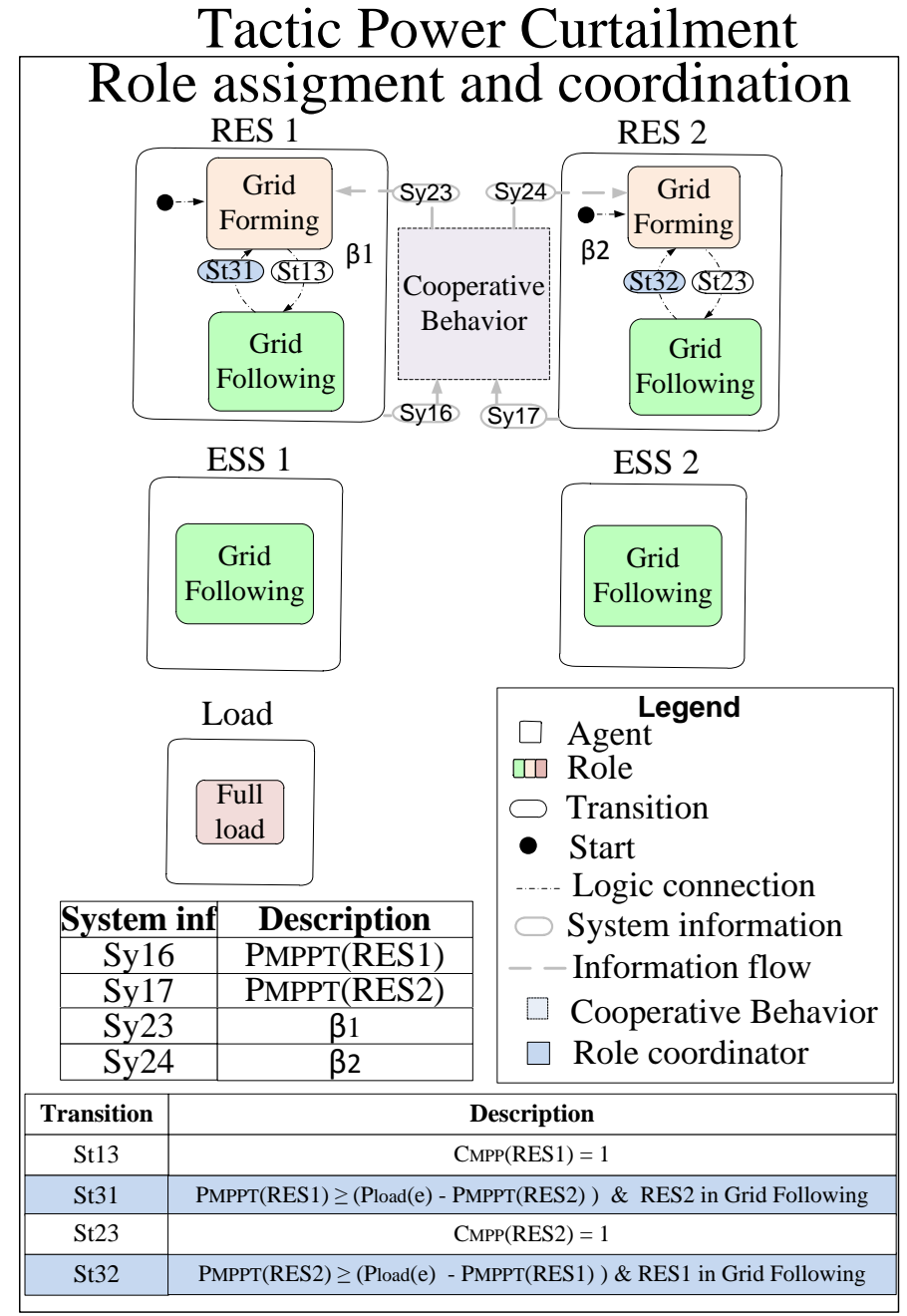

Fig. 13: Role selection and coordination in the tactic Power Curtailment.

$P_{M P P T}($ grid - forming $\left.)\right)$ then, $\left(\operatorname{Ref}\left(P_{\text {RESi }}\right)=1\right)$ and $\left(P^{*}=P_{\text {ext }} i\right)$ where,

$$
P_{\text {ext }} i=0.5 P_{\text {load }(e)}
$$

and, $\left(P_{\text {load }(e)}\right)$ represents the total power consumption of the microgrid, which is calculated as:

$$
P_{\text {load }(e)}=P_{\text {load }}+P_{\text {bat } 1}+P_{\text {bat } 2}
$$

To illustrate, Fig. 14, describes the behaviors selection for RES1 ans RES2 in the grid-following role.

Even so, RESs are able to return to role grid-forming by means of an appropriate role coordination, which activates the transitions St31 and St32. In this proposal, these transitions are activated in the case that one of the RESs units is in the grid-forming role (e.g RES1) and the other one is in the grid-following role (e.g RES2). Under this conditions, the maximum power available from the grid-forming unit droops below the power currently supplied $\left(C_{M P P T}(R E S 1)=1\right)$. At this moment, the other RES unit (RES2) may re-assume the gridforming role if the maximum available power in that unit

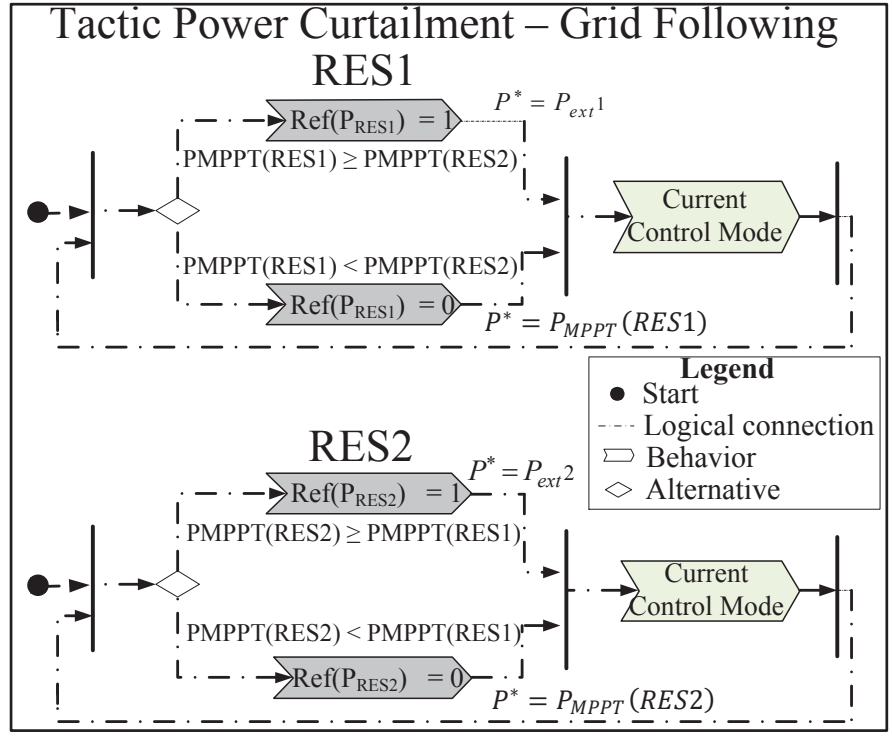

Fig. 14: Behaviors of RES1 and RES2 for the gridfollowing role, tactic Power Curtailment.

is bigger than or equal the difference between the power consumption and the power generation of the other RES $\left(P_{M P P T}(R E S 2) \geq P_{\text {load }(e)}-P_{M P P T}(R E S 1)\right)$.

In fact, the transitions St31 and St32 are defined as shown in the transition table of Fig. 13. From the metaphoric point of view, this kind of role coordination is used in the robot-soccer framework when a defender in the possession of the ball has the clear path to the attack. In this case, the defender assumes the role of attacker and at the same time another agent in the role of attacker moves backwards to the defensive zone and assumes the role of defender in order to support the defensive tactic of the team. Based on this role coordination, it is possible to say that the roles of the agents in the microgrid are assigned dynamically, in accordance to the microgrid operational conditions.

As mentioned before, RESs assume two different roles depending on the microgrid operational conditions. When both RESs are grid-forming units (see Fig. 5d), the power balance is shared between them by means of droop control loops. In this case, cooperative behaviors can be defined in order to set the power contribution of each RES in accordance to its maximum generation capacity. In other words, The RES unit with more available power will contribute more than the others. To achieve this cooperative behavior, the $(P-\omega)$ droop coefficient $K_{p}$ in (1) is weighted by a factor $\beta$ which will adjust the power contribution of each RES unit $\left(P_{R E S i}\right)$ proportionally to its maximum power $\left(P_{M P P T}(R E S i)\right)$. For that reason, the $(P-\omega)$ droop equation described in (1) is modified as:

$$
\omega=\omega^{*}-\beta_{i} \cdot K_{p} \cdot P_{R E S i}
$$

where, the parameters $\beta_{1}$ and $\beta_{2}$ are calculated based on the Algorithm 2. The main idea behind the Algorithm 2 is to assign the biggest weighting factor to the RES 


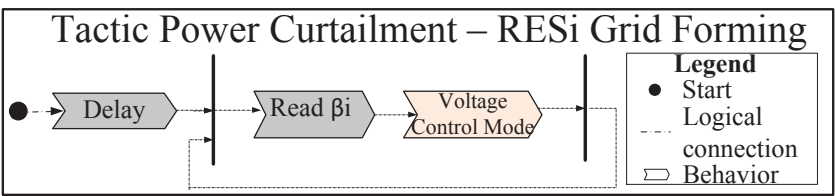

Fig. 15: Behavior of the i-th RES in the grid forming role, tactic Power Curtailment.

unit with the smallest power generation. In Fig. 13, the outputs of the cooperative behavior are the signals $S y 23$ and $S y 24$ which correspond to the parameters $\beta_{1}$ and $\beta_{2}$ respectively, and the inputs of cooperative behavior are the signals $S y 16$ and $S y 17$ which correspond to the maximum power available at each RES $\left(P_{M P P T}(R E S 1)\right)$ and $\left(P_{M P P T}(R E S 2)\right)$ respectively. Apart from that, Fig. 15 shows the behaviors defined for RESs in the role gridforming under the tactic Power Curtailment. Firstly, the behavior description has a delay in order to overcome transitory responses. Afterward, the RESs must work in VCM by considering the value of $\beta_{i}$ for the droop control loop.

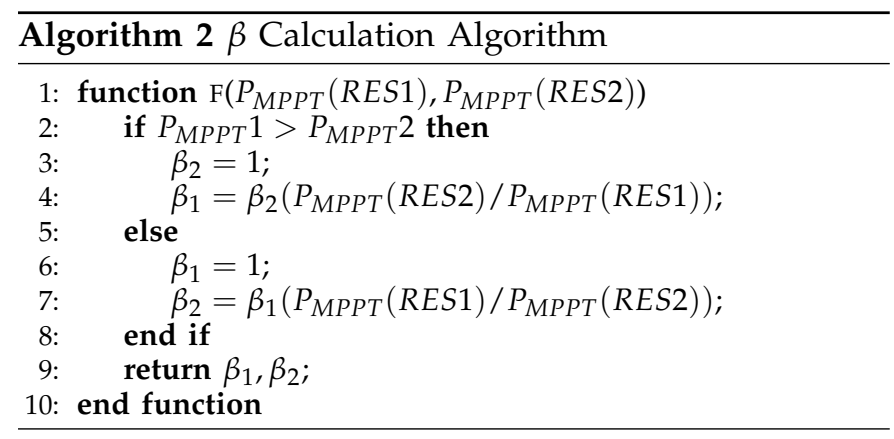

For this tactic, the grid-following role, performed by the ESSs, and Full-Load, performed by the load, are similar than the described in the tactic Power Balance.

\section{Tactic Load Shedding}

In this tactic, RESs and ESSs agents have constant roles. Both RESs perform the grid-following role, with the behaviors sequence described in Fig. 10. Meanwhile, ESSs perform the grid-forming role, with similar behavior sequences than the described in Fig. 11. Also, the equalization algorithm continues working as a cooperative behavior in order to balance the stored energy between distributed ESSs during the discharging process.

Besides, the Load assumes the Load-Adjustment role whose behavior is described in Fig. 16. This tactic has been considered in the case where there is not enough energy to support the load and the ESSs are reaching critical levels of stored energy. Since it is important to avoid full discharges of the batteries, regarding that partial discharge reduces the stress and prolongs the battery life. In this case, two threshold values will be considered for the disconnection of the loads (LVD1) which corresponds to a battery voltage value where the $\mathrm{SoC}$ is aproximately

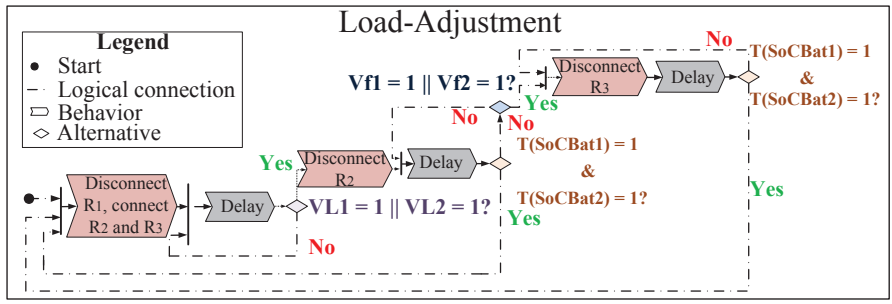

Fig. 16: Behavior of the load in the load-adjustment role, tactic Load-Shedding.

smaller than $50 \%$, and (LVD2) which corresponds to the end-of-discharge voltage recommended by the manufactures (typically 1.85 volts/cell). Therefore, the process for the disconnection of the loads will consider first the disconnection of the less-critical loads and then moves toward the disconnection of more-critical load. In this case three different loads have been considered in the microgrid, being $R_{1}$ the less-critical and $R_{3}$ the most critical one. The disconnection of $R_{3}$ is a last resort to balance the system and avoid deeper discharge of batteries.

When this tactic is activated, the non-critical load $(R 1)$ is disconnected, maintaining connected the loads $\left(R_{2}\right)$ and $\left(R_{3}\right)$. Subsequently, if the voltage at any of the ESSs reaches again the LVD1 value $(V L 1=1$ or $V L 2=1)$ then $R_{2}$ will be disconnected. Finally, if the LVD2 level is reached at any of the ESSs, the status signals $((V f 1$ or $V f 2)$ in Fig. 16) will indicate the disconnection of the critical load $\left(R_{3}\right)(V f 1=1$ or $V f 2=1)$. This is considered as a last resort for avoiding deeper discharge of the batteries.

On the other hand, for the re-connection of the loads, SoC levels at both ESSs will be considered. For the proposed strategy, when the SoC of both ESSs is bigger than or equal to $40 \% R_{3}$ and $R_{2}$ will be connected again $(T($ SoCBat 1$)=1 \& T($ SoCBat 2$)=1)$. As was mentioned before, if the SoC in both ESSs is bigger than or equal to $60 \% R_{1}$ will be re-connected and the tactic of the microgrid will change to Power Balance.

\section{E. Secondary Control}

One of the main advantages of the proposed centralized strategy, is that frequency and voltage restoration strategies can be applied in order to correct the voltage and frequency deviations [3]. Of course, this secondary control is always an option which can be ignored in cases when the maximum frequency and voltage deviation remain within an allowable range. Nevertheless, for this application a secondary controller does not represent an additional deployment of resources, since a central control unit obtains the information from all the agents and the communication channel between agents is already established. Although, centralized restoration of common bus voltage and frequency is not the main scope of this paper. Secondary controllers have been applied in this system as proposed in [11]. Fig. 17 


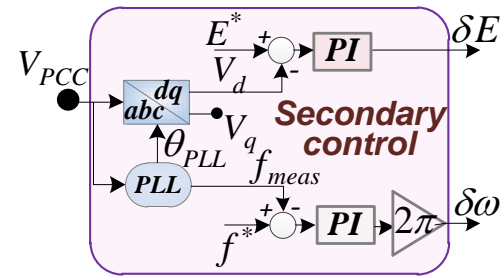

Fig. 17: Central secondary controllers.

shows the scheme of the secondary proportional integral controllers for voltage a frequency restoration. Here, the common bus voltage $\left(V_{P C C}\right)$ is measured and compared with the reference values $\left(f^{*}\right.$ and $\left.E^{*}\right)$ in order to obtain the restoration signals $\delta \omega$ and $\delta E$ which are sent to all the distributed agents (RESs and ESSs) to be included in their voltage control loop.

In light of the above, the droop control loops for ESSs and RESs will be modified as

$$
\begin{gathered}
\omega= \begin{cases}\omega^{*}-\alpha_{i} K_{p} \cdot P_{b a t i}+\delta \omega, & \text { for } E S S i ; \\
\omega^{*}-\beta_{i} K_{p} \cdot P_{R E S i}+\delta \omega, & \text { for } R E S i .\end{cases} \\
E= \begin{cases}E^{*}-K_{q} \cdot Q_{b a t i}+\delta E, & \text { for } E S S i ; \\
E^{*}-K_{q} \cdot Q_{R E S 1}+\delta E, & \text { for } R E S i ;\end{cases}
\end{gathered}
$$

\section{EXPERIMENTAL SETUP DESCRIPTION}

In order to test the proposed control architecture, an experimental setup was used for emulating a low voltage ac microgrid. Fig. 18 shows the configuration of the experimental setup which is divided into a hardware and a real time simulation stages. The hardware part is composed by four inverters Danfoss $(2.2 \mathrm{~kW})$, LCL filters and measurement LEM sensors. Fig. 19 shows an image of the experimental setup in the Microgrid Laboratory of Aalborg University. On the other hand, the real time simulation stage is implemented in a dSPACE1006 control board which emulates the behaviors of the battery models and renewable generators. In addition, the real time simulation stage includes the primary, secondary and central controllers for the proposed coordination strategy. For each battery array, an aggregated model as proposed in [45] is obtained based on the $48 \mathrm{~V}$ battery array model proposed in [46]. Apart from that, a stiff do bus is used for supplying all the inverters. Because of this, RESs are emulated as constant power generators. A full-duplex communication channel has been considered between the centralized control and all the agents where, the data sent from each RES agent $\left(X_{R E S i}\right)$, each ESS agent $\left(X_{E S S i}\right)$, and the load agent $\left(X_{L O A D}\right)$ are defined as

$$
\begin{gathered}
X_{R E S i}=\left[P_{R E S i}, P_{M P P T}(R E S i),\left[C_{M P P T}(R E S i)\right]\right]^{T} \\
X_{E S S i}=\left[K_{\text {bati }}, S o C_{\text {bati }},\right. \\
\left.\left[V H i, V L i, V \text { fi, Sing }\left(P_{\text {bati }}\right), \operatorname{Socci}, T(\text { SoCBati })\right]\right]^{T} \\
X_{L O A D}=\left[P_{\text {load }}, V_{d}, f_{\text {meas }}\right]^{T}
\end{gathered}
$$

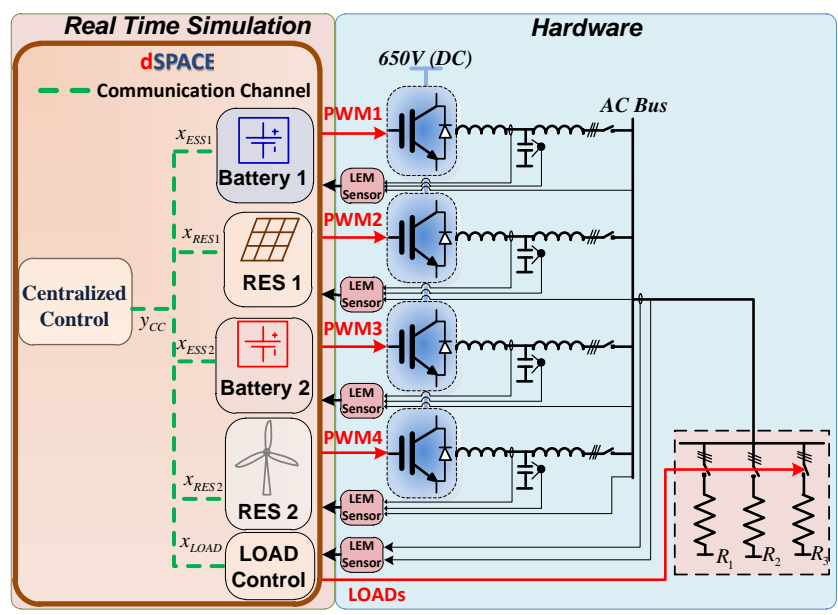

Fig. 18: Experimental setup configuration.

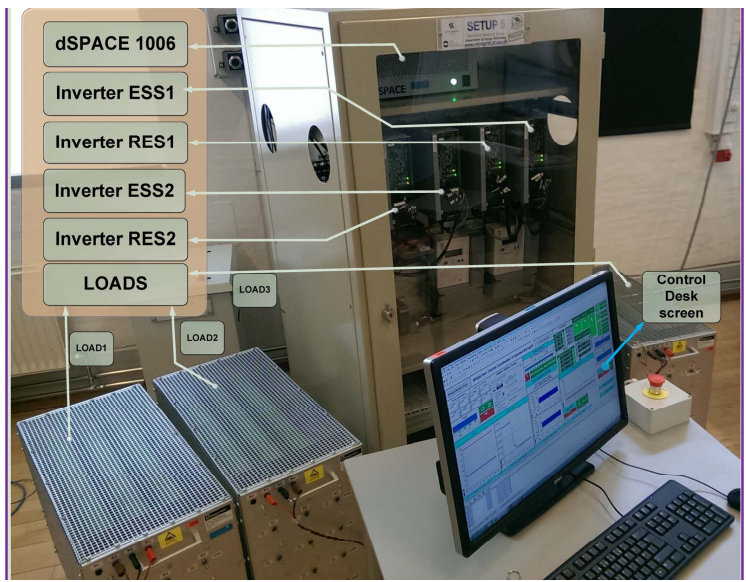

Fig. 19: Image of the Experimental Setup

Likewise, the data sent from the centralized controller to each agent $Y_{C C}$, is defined as

$Y_{C C}= \begin{cases}{\left[\alpha_{i}, \Delta E, \Delta f,[E s s i]\right]^{T},} & \text { for } E S S i ; \\ {\left[\beta_{i}, \Delta E, \Delta f,\left[\operatorname{Resi}, \operatorname{Ref}\left(P_{R E S i}\right)\right]\right]^{T},} & \text { for } \operatorname{RESi} ; \\ {[L O A D s],} & \text { for } L O A D .\end{cases}$

For the small scale microgrid proposed in this paper, the effect of the communication delay was assumed to be negligible. This assumption can be done by selecting the appropriate communication network. In this case, a wired local area network (LAN) is preferred rather than a wireless network. This fact, increases the reliability and reduce communication impairments, such as packet delays and losses [47]. For instance, switched Ethernet have been widely implemented for industrial networked control systems [48]. In the case of a simple Ethernet network, the estimated latency for a light network load (such as the proposed in this case study microgrid) is about $127 \mu$ s, under full-size frame of 1518 bytes, and up to $1.85 \mathrm{~ms}$ in the worst-case [49]. This latency is mainly due to the processing performed by the protocol, while the propagation delay can be neglected especially in LAN applications [47]. Apart from that, previous 
analysis on the impact of communication latency in central secondary control, such as in [50], show that the microgrid is able to keep a good performance for communication delays up to $200 \mathrm{~ms}$ which is bigger compared to the worst latency in a switched Ethernet network. From the point of view of the coordinated strategy, the effect of communication delay can also be neglected. To be more precise, by considering that the dynamic response of the microgrid mainly depends on the time required for charging a battery (seconds, minutes or hours depending on the battery capacity), the latency introduced by the LAN can be neglected.

Table I summarizes the main parameters of the microgrid considered for evaluating the coordinated strategy. The capacity of batteries is set at $0.016 \mathrm{Ah}$ in order to speed up the charge and discharge process for validating the strategy.

As a matter of fact, the nominal values of the droop coefficients $\left(K_{p}\right.$ and $\left.K_{q}\right)$ have been selected based on small signal stability constrains as is explained in [51]. Based on the methodology previously proposed in [51], it is possible to evaluate the stability of the islanded microgrid under the different topological operation modes presented in Fig. 5. Interested readers may refer to [51] and [52] for further explanation about the stability analysis.

TABLE I: Parameters of the Microgrid

\begin{tabular}{|c|c|c|}
\hline Parameter & Symbol & Value \\
\hline & Power Stage & \\
\hline Nominal Voltage & $E^{*}$ & $120 * \sqrt{2} \mathrm{~V}$ \\
\hline Nominal Frequency & $f^{*}$ & $50 \mathrm{~Hz}$ \\
\hline Inverter inductors & $L 1, L 2$ & $1.8 \mathrm{mH}$ \\
\hline Filter Capacitor & $\mathrm{C} 1$ & $27 \mu \mathrm{F}$ \\
\hline Three-phase & $R_{1}$, & $310 \Omega$ \\
\hline Resistive & $R_{2}$ & $1000 \Omega$, \\
\hline Loads & $R_{3}$ & $456 \Omega$ \\
\hline & Battery Array & \\
\hline Nominal Voltage & Vbat & $348 \mathrm{~V}$ \\
\hline Regulation Voltage & $V_{r}$ & $432 \mathrm{~V}$ \\
\hline Low-Voltage Disconnect & LVD1 & $388 \mathrm{~V}$ \\
\hline End-of-discharge Voltage & $L V D 2$ & $319 \mathrm{~V}$ \\
\hline Battery Capacity & $C_{b a t}$ & $0.016 \mathrm{Ah}$ \\
\hline Equalization time & $\Delta t$ & $5 \mathrm{~s}$ \\
\hline & $\begin{array}{l}\text { Power flow } \\
\text { Control }\end{array}$ & \\
\hline $\begin{array}{l}\text { Droop Coefficient } \\
(P-\omega)\end{array}$ & $K_{p}$ & $\begin{array}{c}1.25 * 10^{-5} \\
(\mathrm{rad}) /(\mathrm{s}) /(\mathrm{W})\end{array}$ \\
\hline $\begin{array}{l}\text { Droop Coefficient } \\
(Q-E)\end{array}$ & $K_{q}$ & $\begin{array}{l}5 * 10^{-4} \\
\mathrm{~V} /(\mathrm{VAr})\end{array}$ \\
\hline $\begin{array}{l}\text { Reactive power } \\
\text { Reference }\end{array}$ & $Q^{*}$ & $0 \mathrm{VAr}$ \\
\hline
\end{tabular}

\section{EXPERIMENTAL RESULTS}

This section presents experimental results obtained from the experimental islanded microgrid, by considering different tactics, roles and behaviors for the distributed agents.

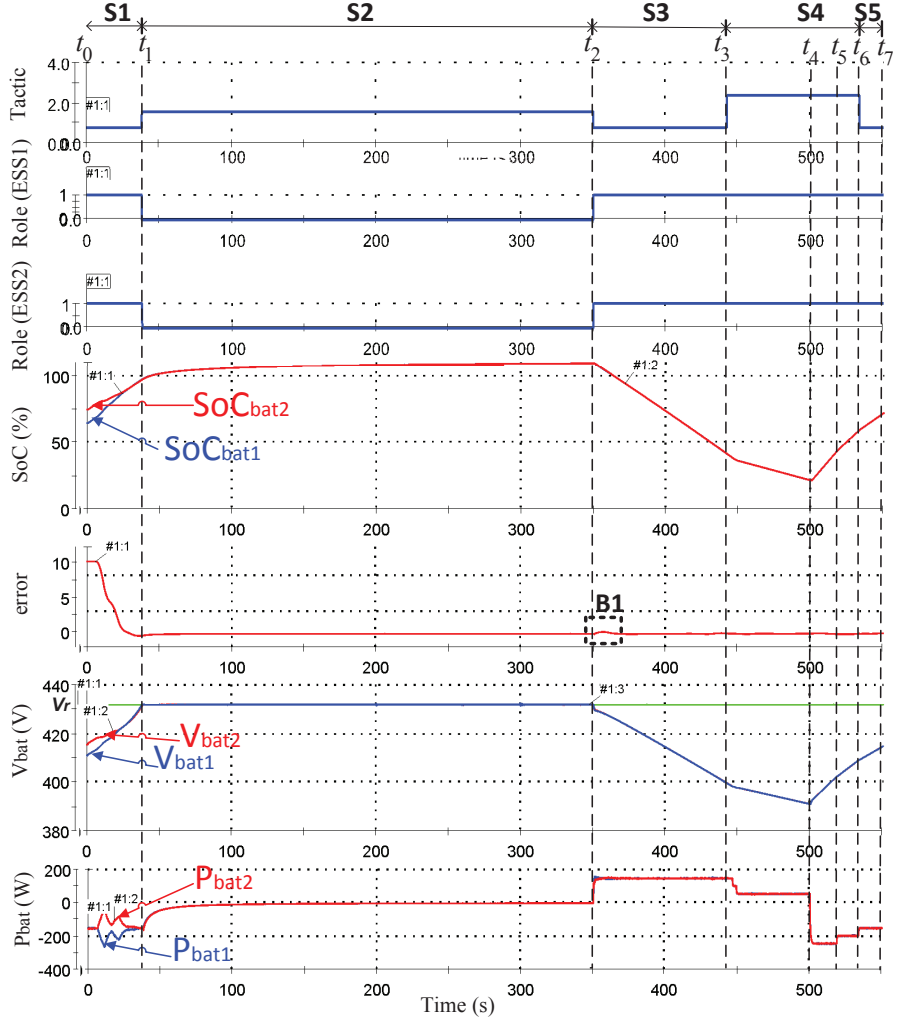

Fig. 20: Experimental results for distributed ESSs

\section{A. Response of ESSs Agents}

Fig. 20, shows the experimental profile from distributed ESSs. At the beginning, different initial SoC's have been considered for the distributed ESSs $\left(S_{0} C_{b a t 1}=\right.$ $65 \%$ and $S_{o} C_{\text {bat } 2}=75 \%$ ). First, in Fig. 20 it is possible to see a status signal which indicates the tactic in which the microgrid is currently operating (Power Balance, Power curtailment and Load Adjustment correspond to 1,2 and 3 respectively). Second, it is possible to see the status signal which indicates the role assigned to each ESS (Grid-Forming=1, Grid-Following=0). Third, it is possible to see the $\mathrm{SoC}$, the error value, defined as $\left(\right.$ error $\left.=S_{o} C_{b a t 2}-S o C_{b a t 1}\right)$, the voltage at each battery array and the power shared between distributed ESSs. For a better explanation Fig. 20 is divided in five stages (S1 to S5) as follows:

S1 $\left(t_{0}-t_{1}\right)$ : RESs are generating more energy than the power consumption therefore the ESSs are being charged. Accordingly, the current tactic of the microgrid is Power Balance (tactic $=1$ ). Meanwhile, the cooperative behavior between agents (equalization algorithm) is being applied for SoC equalization. As can be seen, the power at each ESS is adjusted while the batteries are charged in order to reduce the error value to zero.

S2 $\left(t_{1}-t_{2}\right)$ : At $t_{1}$ both battery arrays reach the regulation voltage value $V_{r}$. In consequence, RESs assume the regulation of the common bus and the tactic of the microgrid changes to Power Curtailment (tactic=2). At this point, the ESSs changes their role to grid-following as can be 


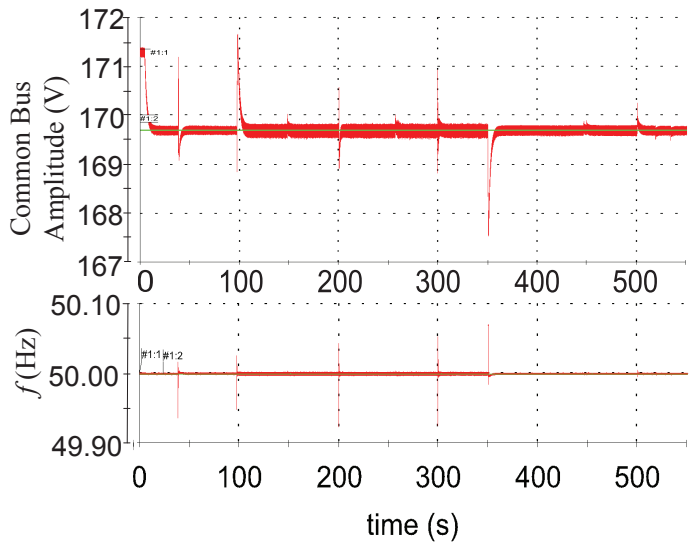

Fig. 21: Common bus voltage and frequency with secondary control

seen in Fig. $20(\operatorname{Role}(E S S 1)=0$ and Role $(E S S 2)=0)$.

S3 $\left(t_{2}-t_{3}\right)$ : At $t_{2}$ there is not enough energy available from RESs. As a result, ESSs will assume again the grid-forming role, and the ESSs will be discharged to keep the power balance in the microgrid. The microgrid returns to the tactic Power Balance. The equalization algorithm ensures that any difference in the SoC's caused by circulating currents, that may appear when the ESSs re-assume the grid-forming role, is restored to zero [53]. The effect of circulating currents in the error signal can be seen as a small peak marked by the box B1 drawn in the error signal of Fig. 20.

S4 $\left(t_{3}-t_{6}\right)$ : At $t_{3}$ the voltages at the ESSs drop until LVD1. Therefore, the microgrid changes its tactic to Load Adjustment (tactic $=3$ ) where, $R_{1}$ and subsequently $R_{2}$ are disconnected. At $t_{4}$ the ESSs start again their process of charge because of this, in $t_{5} R_{2}$ is connected again $\left(S o C_{b a t 1} \& S o C_{b a t 2} \geq 40 \%\right)$. From $t_{5}$ to $t_{6}$ the ESSs continue being charged.

S5 $\left(t_{6}-t_{7}\right)$ : At $t 6$ when $\left(S o C_{b a t 1} \& S o C_{b a t 2} \geq 60 \%\right) R_{1}$ is connected to the local grid and the microgrid returns to the Power Balance tactic.

Apart from that, Fig. 21 shows the profile of the common voltage and frequency during the operation of the microgrid. In Fig. 21, it is possible to see the effect of the secondary controllers in order to keep the common bus voltage and frequency in their reference value, in steady state. The secondary control is activated in $t 1$.

\section{B. Response of RESs Agents}

Fig. 22, shows the experimental profile of the distributed RESs. First, in Fig. 22 it is presented the status signal which indicates the current tactic of the microgrid. Second, it is possible to see the status signal which indicates the role assigned to RES1 (Role(RES1)). Third, Fig. 22 shows the status signal $\left(\operatorname{Ref}\left(P_{R E S 1}\right)\right)$ which indicates the different behaviors assigned to RES1 under gridfollowing operation (see equation (7)). Fourth, in Fig. 22 it is possible to see the maximum power reference $\left(P_{M P P T}\right)$ and the generated power $P_{R E S 1}$ of the RES1.

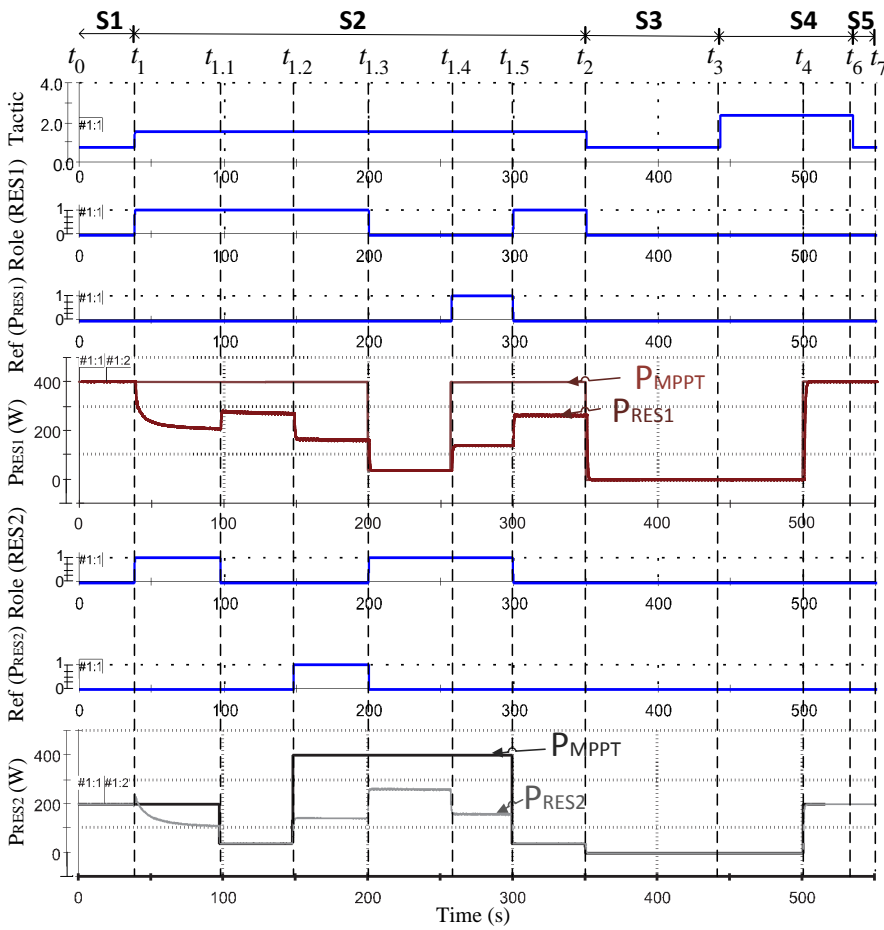

Fig. 22: Experimental results of the distributed RESs

Subsequently, Fig. 22 shows the status signal of the role assigned to RES2 (Role(RES2)), the status signal $\left(\operatorname{Re} f\left(P_{R E S 2}\right)\right)$ and the power profile for RES2. Like in the previous subsection, Fig. 22 is divided in five stages (S1 to S5) which correspond to the operation of the microgrid under different tactics.

S1 $\left(t_{0}-t_{1}\right)$ : During this stage the microgrid operates in Power Balance (tactic $=1$ ). Then, RESs provide more energy than the load consumption and the surplus of energy is used to charge the ESSs. In this case, RESs follow the reference defined by the MPPT algorithm $\left(P_{M P P T}(R E S 1)=400 \mathrm{~W}\right.$ and $\left.P_{M P P T}(R E S 2)=200 \mathrm{~W}\right)$.

S2 $\left(t_{1}-t_{2}\right)$ : In this stage, the microgrid operates in Power Curtailment (tactic $=2$ ). Because of that, RESs are the responsible for ensuring the power balance in the microgrid. Initially, from $t_{1}$ to $t_{1.1}$ both RESs are operating as grid-forming units (Role $(R E S 1)=1$ and $\operatorname{Role}($ RES2 $)=1)$ then, the power is shared between them proportionally to their maximum power reference. As can be seen, RES1 supplies more power than RES2. From $t_{1.1}$ to $t_{1.2}$, the maximum power injected from RES2 is reduced $\left(P_{M P P T}(R E S 2)=40 \mathrm{~W}\right)$. For that reason, RES2 changes its role to grid-followig $(\operatorname{Role}(R E S 2)=0)$ and RES1 continues in the grid-forming role.

At $t_{1.2}$, the maximum power from RES2 increases $\left(P_{M P P T}(R E S 2)=400 \mathrm{~W}\right)$ but RESs do not change their roles. However, there is a change in the behavior of RES2 $\left(\operatorname{Ref}\left(P_{R E S 2}=1\right)\right)$ and the power reference $\left(P^{*}\right)$ is defined in accordance to equation (9) (for more details refer to equation (7) and Figs. 13 and 14).

From $t_{1.3}$ to $t_{1.4}$, the maximum power from RES1 is reduced $\left(P_{M P P T}(R E S 1)=40 \mathrm{~W}\right)$. Because of that, there is 
a coordination between roles. That is, RES1 assumes the grid-following role, and RES2 assumes the grid-forming role, since RES2 has enough energy to ensure the power balance of the system. During this period, the power reference for RES1 is imposed by the MPPT algorithm.

At $t_{1.4}$, the maximum power from RES1 increases $\left(P_{M P P T}(R E S 1)=400 \mathrm{~W}\right)$. As a result, there is a change in the behavior of RES1 $\left(\operatorname{Ref}\left(P_{R E S 1}=1\right)\right)$ and the power reference $\left(P^{*}\right)$ is defined in accordance to (9). Finally, from $t_{1.5}$ to $t_{2}$ the maximum power from RES2 is reduced $\left(P_{M P P T}(R E S 2)=40 \mathrm{~W}\right)$. In that case, due to the coordination of roles RES1 assumes the grid-forming role, while RES2 assumes the grid-following role by supplying its maximum available power.

S3 $\left(t_{2}-t_{3}\right)$ : At $t_{2}$ the maximum power in both RESs is set to zero $\left(P_{M P P T}(R E S 1)=0 \mathrm{~W}\right.$ and $\left.P_{M P P T}(R E S 2)=0 \mathrm{~W}\right)$. Because of that, there is a change in the tactic of the microgrid (tactic=2). As a result, ESSs re-assume the gridforming role where they will be discharged to ensure the power balance in the microgrid.

S4 $\left(t_{3}-t_{6}\right)$ : During this period the microgrid operates in the tactic Load Adjustment (tactic=3). At $t_{4}$ RESs increase their maximum power $\left(P_{M P P T}(R E S 1)=400 \mathrm{~W}\right.$ and $\left.P_{M P P T}(R E S 2)=200 \mathrm{~W}\right)$ and the ESSs start to be recharged.

S5 $\left(t_{6}-t_{7}\right)$ : At $t 6$ the microgrid returns to Power Balance (tactic $=1$ ) and the RESs agents operate as grid-following units by following the power reference imposed by the MPPT algorithm.

\section{Response of LOAD agent}

To conclude with the results, Fig. 23 shows the load profile during the operation of the islanded microgrid. First, Fig. 23 presents the status signal which represents the microgrid tactic. Second, it is possible to see a status signal that represents the role of the load. In this case $($ Role $($ Load $)=0)$ when $R_{1}, R_{2}$ and $R_{3}$ are connected, $($ Role $($ Load $)=1)$ when $R_{2}$ and $R_{3}$ are connected, and $(\operatorname{Role}($ Load $)=2)$ which means that only $R_{3}$ is connected. During the first three stages (S1, S2 and S3) the load seen as an agent- has a constant role and behavior (FullLoad). Just during S4, the load is adjusted in accordance to the ESSs threshold values defined previously. In this case, the disconnection of $R_{1}$ and $R_{2}$ is very fast (see the box B2 in Fig. 23) then, Fig. 24 shows an enlarged version of the box B2. It is possible to see how the power consumption of the load is adjusted. The smooth transition that is shown in Fig. 24, is due to the use of measuring filters in the measurement block [51].

At $t_{5}:\left(S_{o} C_{b a t 1} \& S o C_{b a t 2} \geq 40 \%\right)$ then, $R_{2}$ is connected. After a while, at $t_{6}:\left(S o C_{b a t 1} \& S o C_{b a t 2} \geq 60 \%\right)$ then, $R_{1}$ is connected and the microgrid changes its tactic to Power Balance (tactic $=1$ ).

\section{CONCLUSION}

In this paper a novel control architecture inspired in well-known architecture strategies for robot soccer

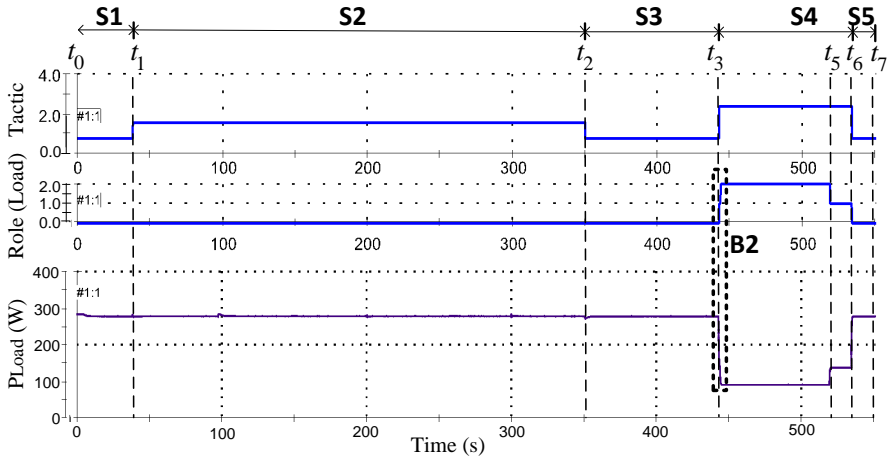

Fig. 23: Experimental results for the LOAD agent

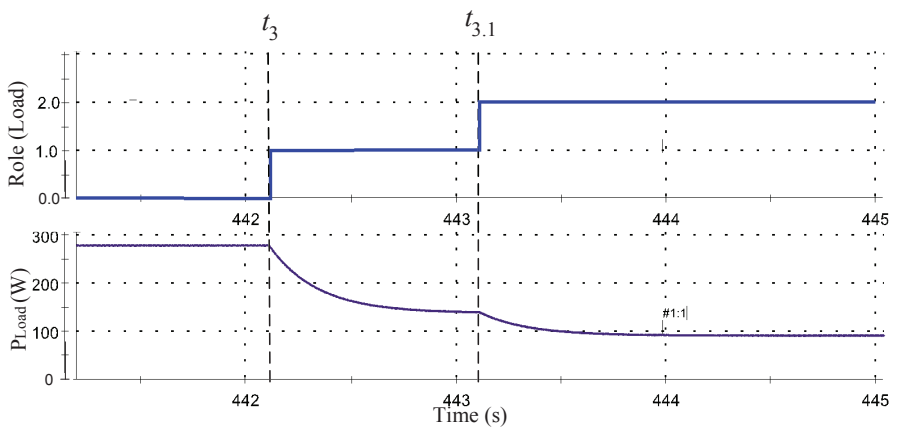

Fig. 24: Box B2 in Fig. 24

coordination has been adapted to an islanded microgrid. The strategy presented, proposed a novel multi-agent architecture for a coordinated operation of an islanded microgrid, based on hardware agents (DERs), which can play a role (grid-forming, grid-following) depending on a tactic previously selected (power balance, power curtailment, load shedding). The proposed centralized strategy adds more flexibility to the operation of the distributed agents since it makes possible the definition of additional collaborative behaviors between distributed energy resources such as reactive power or harmonic compensation. On top of that, the proposed centralized architecture allows a reliable coordination and transition between operation modes for the distributed energy resources. What is more, additional functions such as voltage and frequency restoration can be applied in order to achieve a better regulation of the common bus without losing the coordination between distributed units. The proposed approach opens a new perspective for the use of other centralized or distributed techniques applied in cooperative robotic for the coordinated operation of a microgrid, extensible into smart grids and other networked energy systems.

\section{REFERENCES}

[1] D. Wu, F. Tang, T. Dragičević, J. Vasquez, and J. Guerrero, "A control architecture to coordinate renewable energy sources and energy storage systems in islanded microgrids," IEEE Transactions on Smart Grid, vol. 6, pp. 1156-1166, May 2015. 
[2] H. Mahmood, D. Michaelson, and J. Jiang, "Strategies for independent deployment and autonomous control of pv and battery units in islanded microgrids," IEEE Journal of Emerging and Selected Topics in Power Electronics, vol. 3, pp. 742-755, Sept 2015.

[3] J. Pecas Lopes, C. Moreira, and A. Madureira, "Defining control strategies for microgrids islanded operation," IEEE Transactions on Power Systems, vol. 21, pp. 916-924, May 2006.

[4] J. Rocabert, A. Luna, F. Blaabjerg, and P. Rodríguez, "Control of power converters in ac microgrids," IEEE Transactions on Power Electronics, vol. 27, pp. 4734-4749, Nov 2012.

[5] T. Vandoorn, J. Vasquez, J. De Kooning, J. Guerrero, and L. Vandevelde, "Microgrids: Hierarchical control and an overview of the control and reserve management strategies," IEEE Industrial Electronics Magazine, vol. 7, pp. 42-55, Dec 2013.

[6] D. Linden and T. Reddy, Handbook of batteries. McGraw-Hill handbooks, McGraw-Hill, 2002.

[7] "IEEE Guide for Optimizing the Performance and Life of LeadAcid Batteries in Remote Hybrid Power Systems," IEEE Std 15612007, pp. C1-25, May 2008.

[8] A. H. Fathima and K. Palanisamy, "Optimization in microgrids with hybrid energy systems a review," Renewable and Sustainable Energy Reviews, vol. 45, pp. 431 - 446, 2015.

[9] F. Katiraei, R. Iravani, N. Hatziargyriou, and A. Dimeas, "Microgrids management," IEEE Power and Energy Magazine, vol. 6, pp. 54-65, May 2008.

[10] W. Shi, X. Xie, C.-C. Chu, and R. Gadh, "Distributed optimal energy management in microgrids," IEEE Transactions on Smart Grid, vol. 6, pp. 1137-1146, May 2015.

[11] D. Wu, F. Tang, T. Dragičević, J. Vasquez, and J. Guerrero, "Autonomous active power control for islanded ac microgrids with photovoltaic generation and energy storage system," IEEE Transactions on Energy Conversion, vol. 29, pp. 882-892, Dec 2014.

[12] M. Sechilariu, B. C. Wang, and F. Locment, "Supervision control for optimal energy cost management in $\{D C\}$ microgrid: Design and simulation," International Journal of Electrical Power \& Energy Systems, vol. 58, pp. $140-149,2014$.

[13] B. Wang, M. Sechilariu, and F. Locment, "Intelligent dc microgrid with smart grid communications: Control strategy consideration and design," IEEE Transactions on Smart Grid, vol. 3, pp. 21482156, Dec 2012.

[14] M. Mao, H. Huang, and L. Chang, "Real-time energy coordinated and balance control strategies for microgrid with photovoltaic generators," in 4th IEEE International Symposium on Power Electronics for Distributed Generation Systems (PEDG), pp. 1-7, July 2013.

[15] N. Diaz, D. Wu, T. Dragicevic, J. Vasquez, and J. Guerrero, “Fuzzy droop control loops adjustment for stored energy balance in distributed energy storage system," in 9th International Conference on Power Electronics and ECCE Asia (ICPE-ECCE Asia), pp. 728-735, June 2015.

[16] P. Nguyen, W. Kling, and P. Ribeiro, "A game theory strategy to integrate distributed agent-based functions in smart grids," IEEE Transactions onSmart Grid, vol. 4, pp. 568-576, March 2013.

[17] L. Hernandez, C. Baladron, J. Aguiar, B. Carro, A. SanchezEsguevillas, J. Lloret, D. Chinarro, J. Gomez-Sanz, and D. Cook, "A multi-agent system architecture for smart grid management and forecasting of energy demand in virtual power plants," IEEE Communications Magazine, vol. 51, pp. 106-113, January 2013.

[18] C. Nguyen and A. Flueck, "Agent based restoration with distributed energy storage support in smart grids," IEEE Transactions on Smart Grid, vol. 3, pp. 1029-1038, June 2012.

[19] B. Ramachandran, S. Srivastava, C. Edrington, and D. Cartes, "An intelligent auction scheme for smart grid market using a hybrid immune algorithm," IEEE Transactions on Industrial Electronics, vol. 58, pp. 4603-4612, Oct 2011.

[20] H. Dagdougui and R. Sacile, "Decentralized control of the power flows in a network of smart microgrids modeled as a team of cooperative agents," IEEE Transactions on Control Systems Technology, vol. 22, pp. 510-519, March 2014.

[21] O. Palizban, K. Kauhaniemi, and J. M. Guerrero, "Microgrids in active network managementpart i: Hierarchical control, energy storage, virtual power plants, and market participation," Renewable and Sustainable Energy Reviews, vol. 36, pp. 428 - 439, 2014.

[22] W. Liu, W. Gu, W. Sheng, X. Meng, Z. Wu, and W. Chen, "Decentralized multi-agent system-based cooperative frequency control for autonomous microgrids with communication constraints," IEEE Transactions on Sustainable Energy, vol. 5, pp. 446-456, April 2014.
[23] Q. Li, F. Chen, M. Chen, J. Guerrero, and D. Abbott, "Agentbased decentralized control method for islanded microgrids," IEEE Transactions on Smart Grid, vol. PP, no. 99, pp. 1-1, 2015.

[24] C. xia Dou and B. Liu, "Multi-agent based hierarchical hybrid control for smart microgrid," IEEE Transactions on Smart Grid, vol. 4, pp. 771-778, June 2013.

[25] A. Farinelli, L. Iocchi, and D. Nardi, "Multirobot systems: a classification focused on coordination," IEEE Transactions on Systems, Man, and Cybernetics, Part B: Cybernetics, vol. 34, pp. 2015-2028, Oct 2004

[26] F. Stulp, H. Utz, M. Isik, and G. Mayer, "Implicit coordination with shared belief: A heterogeneous robot soccer team case study," Advanced Robotics, vol. 24, no. 7, pp. 1017-1036, 2010.

[27] J. G. Guarnizo, J. F. Blanes, M. Mellado, S. J., and M. Muñoz, "A survey of team strategies in robot soccer, focused on standard platform league," in XIII Workshop on Physical Agents, pp. 193-200, September 2012.

[28] B. Browning, J. Bruce, M. Bowling, and M. Veloso, "Stp: Skills, tactics and plays for multi-robot control in adversarial environments," IEEE Journal of Control and Systems Engineering, vol. 219, pp. 33-52, 2005.

[29] C. Agüero, V. Matellan, V. Gomez, and J. Cañas, "Switch! dynamic roles exchange among cooperative robots," in 3rd International Conference on Informatics in Control, August 2006. http://hdl.handle.net/10612/1999.

[30] N. Lau, L. Lopes, G. Corrente, and N. Filipe, "Multi-robot team coordination through roles, positionings and coordinated procedures," in IEEE/RSJ International Conference on Intelligent Robots and Systems (IROS)., pp. 5841-5848, Oct 2009.

[31] J. G. Guarnizo, M. Mellado, C. Y. Low, and F. Blanes, "Architecting centralized coordination of soccer robots based on principle solution," Advanced Robotics, vol. 29, no. 15, pp. 963-978, 2015.

[32] F. Katiraei, R. Iravani, N. Hatziargyriou, and A. Dimeas, "Microgrids management," IEEE Power and Energy Magazine, vol. 6, pp. 54-65, May 2008.

[33] F. Marra, G. Yang, C. Traeholt, J. Ostergaard, and E. Larsen, "A decentralized storage strategy for residential feeders with photovoltaics," IEEE Transactions on Smart Grid, vol. 5, pp. 974981, March 2014.

[34] M. Ross, C. Abbey, and G. Joos, "A methodology for optimized energy storage sizing with stochastic resources," in IEEE Power and Energy Society General Meeting (PES), pp. 1-5, July 2013.

[35] M. Fazeli, G. Asher, C. Klumpner, L. Yao, and M. Bazargan, "Novel integration of wind generator-energy storage systems within microgrids," IEEE Transactions on Smart Grid, vol. 3, pp. 728-737, June 2012.

[36] E. Liegmann and R. Majumder, "An efficient method of multiple storage control in microgrids," IEEE Transactions on Power Systems, vol. 30, pp. 3437-3444, Nov 2015.

[37] A. Mohd, E. Ortiohann, A. Schmelter, N. Hamsic, and D. Morton, "Challenges in integrating distributed energy storage systems into future smart grid," in IEEE International Symposium on Industrial Electronics (ISIE), pp. 1627-1632, June 2008.

[38] J. de Matos, F. S.F.e Silva, and L. de S Ribeiro, "Power control in ac isolated microgrids with renewable energy sources and energy storage systems," IEEE Transactions on Industrial Electronics, vol. 62, pp. 3490-3498, June 2015.

[39] C. Li, H. Shi, Y. Cao, J. Wang, Y. Kuang, Y. Tan, and J. Wei, "Comprehensive review of renewable energy curtailment and avoidance: A specific example in china," Renewable and Sustainable Energy Reviews, vol. 41, pp. 1067 - 1079, 2015.

[40] J. Guerrero, L. Garcia De Vicuna, J. Matas, M. Castilla, and J. Miret, "A wireless controller to enhance dynamic performance of parallel inverters in distributed generation systems," IEEE Transactions on Power Electronics, vol. 19, pp. 1205-1213, Sept 2004.

[41] R. Majumder, "Some aspects of stability in microgrids," IEEE Transactions on Power Systems, vol. 28, pp. 3243-3252, Aug 2013.

[42] N. L. Diaz, D. Wu, T. Dragicevic, J. C. Vasquez, and J. M. Guerrero, "Stored energy balance for distributed pv-based active generators in an ac microgrid," in Power Energy Society General Meeting, 2015 IEEE, pp. 1-5, July 2015

[43] N. Diaz, A. Luna, J. Vasquez, and J. Guerrero, "Energy management system with equalization algorithm for distributed energy storage systems in pv-active generator based low voltage dc microgrids," in IEEE First International Conference on DC Microgrids (ICDCM), pp. 293-298, June 2015. 
[44] N. L. Daz, A. C. Luna, J. C. Vsquez, and J. M. Guerrero, "Equalization algorithm for distributed energy storage systems in islanded ac microgrids," in 41st Annual Conference of the IEEE Industrial Electronics Society, IECON 2015, pp. 004661-004666, Nov 2015.

[45] Z. Miao, L. Xu, V. Disfani, and L. Fan, "An soc-based battery management system for microgrids," IEEE Transactions on Smart Grid, vol. 5, pp. 966-973, March 2014

[46] T. Dragicevic, J. Guerrero, J. Vasquez, and D. Skrlec, "Supervisory control of an adaptive-droop regulated dc microgrid with battery management capability," IEEE Transactions on Power Electronics, vol. 29, pp. 695-706, Feb 2014

[47] Q. Shafiee, C. Stefanovic, T. Dragicevic, P. Popovski, J. Vasquez, and J. Guerrero, "Robust networked control scheme for distributed secondary control of islanded microgrids," IEEE Transactions on Industrial Electronics, vol. 61, pp. 5363-5374, Oct 2014

[48] R. Gupta and M.-Y. Chow, "Networked control system: Overview and research trends," IEEE Transactions on Industrial Electronics, vol. 57, pp. 2527-2535, July 2010.

[49] "Latency on a switched ethernet network," Siemens Canada Limited Application Note 8.

[50] Q. Shafiee, J. Guerrero, and J. Vasquez, "Distributed secondary control for islanded microgrids-a novel approach," IEEE Transactions on Power Electronics, vol. 29, pp. 1018-1031, Feb 2014.

[51] N. Diaz, E. Alves Coelho, J. Vasquez, and J. Guerrero, "Stability analysis for isolated ac microgrids based on pv-active generators," in IEEE Energy Conversion Congress and Exposition (ECCE), pp. 4214-4221, Sept 2015.

[52] E. Coelho, P. Cortizo, and P. Garcia, "Small-signal stability for parallel-connected inverters in stand-alone ac supply systems," IEEE Transactions on Industry Applications, vol. 38, pp. 533-542, Mar 2002

[53] X. Wang, F. Blaabjerg, and Z. Chen, "An improved design of virtual output impedance loop for droop-controlled parallel three-phase voltage source inverters," in IEEE Energy Conversion Congress and Exposition (ECCE), pp. 2466-2473, Sept 2012.

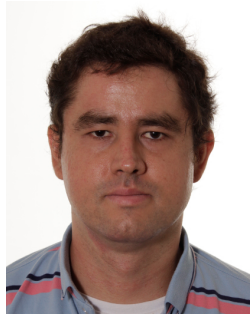

Nelson L. Díaz $\left(\mathrm{S}^{\prime} 09\right)$ received the B.S degree in Electronic Engineering from the Universidad Distrital F.J.C in 2008, and the M.S. degree in Industrial Automation from the Universidad $\mathrm{Na}-$ cional de Colombia in 2011, Bogotá, Colombia. $\mathrm{He}$ is currently pursuing the Ph.D. degree from the Department of Energy Technology, Aalborg University, Aalborg, Denmark. He is member of the Research Laboratory of Alternative Energy Sources, Universidad Distrital F.J.C. and Microgrid Research Group, Aalborg University. His current research interests include microgrids and power converters control.

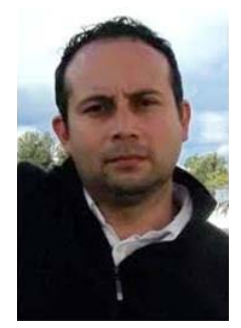

Jose Guillermo Guarnizo is Electronic Engineer of the University Francisco Jose de Caldas of BogotColombia in 2006, and Master in Industrial Automation of the National University of Colombia in 2009. Actually is Ph.D. student in Automatic, Robotics, and Industrial Informatics in Universitat Politècnica de València, and belongs to the Laboratory of Alternative Source of Energy LIFAE of the University Francisco Jos de Caldas of Bogota Colombia, and the Instituto de Automática e Informática Industrial in UPV.

His main research interests are robotics, multi-agent systems, robot soccer architectures, control systems, intelligent systems and power electronics.

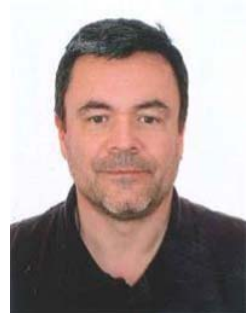

Martin Mellado received the B.Eng. in Computer Science from Universitat Politècnica de València (UPV), Spain in 1987, the MSc degree in Computer Aided Engineering from the School of Mechanical Engineering, Cranfield Institute of Technology, UK in 1989 and the PhD degree in Computer Engineering in UPV in 1996. Nowadays he is a Professor and develops his research in the Instituto de Automática e Informática Industrial in UPV. His main research interests are in the field of food inspection and manipulation with robots, leading more than $12 \mathrm{R} \& \mathrm{D}$ projects in this field.

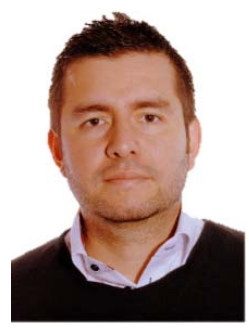

Juan C. Vasquez (M'12-SM'14) received the B.S. degree in electronics engineering from the $\mathrm{Au}$ tonomous University of Manizales, Manizales, Colombia, and the Ph.D. degree in automatic control, robotics, and computer vision from the Technical University of Catalonia, Barcelona, Spain, in 2004 and 2009, respectively. He was with the Autonomous University of Manizales working as a teaching assistant and the Technical University of Catalonia as a Post-Doctoral Assistant in 2005 and 2008 respectively. In 2011, he was Assistant Professor and from 2014 he is working as an Associate Professor at the Department of Energy Technology, Aalborg University, Denmark where he is the Vice Programme Leader of the Microgrids Research Program. From Feb. 2015 to April. 2015 he was a Visiting Scholar at the Center of Power Electronics Systems (CPES) at Virginia Tech. His current research interests include operation, advanced hierarchical and cooperative control, optimization and energy management applied to distributed generation in AC and DC microgrids. He has authored and co-authored more than 100 technical papers only in Microgrids in international IEEE conferences and journals. Dr. Vasquez is currently a member of the IEC System Evaluation Group SEG4 on LVDC Distribution and Safety for use in Developed and Developing Economies, the Renewable Energy Systems Technical Committee TCRES in IEEE Industrial Electronics, PELS, IAS, and PES Societies.

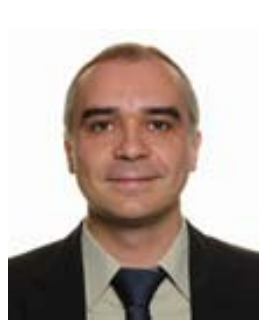

Josep M. Guerrero (S'01-M'04-SM'08-FM'15) received the B.S. degree in telecommunications engineering, the M.S. degree in electronics engineering, and the Ph.D. degree in power electronics from the Technical University of Catalonia, Barcelona, in 1997, 2000 and 2003, respectively. Since 2011, he has been a Full Professor with the Department of Energy Technology, Aalborg University, Denmark, where he is responsible for the Microgrid Research Program. From 2012 he is a guest Professor at the Chinese Academy of Science and the Nanjing University of Aeronautics and Astronautics; from 2014 he is chair Professor in Shandong University; from 2015 he is a distinguished guest Professor in Hunan University; and from 2016 he is a visiting professor fellow at Aston University, UK. His research interests is oriented to different microgrid aspects, including power electronics, distributed energy-storage systems, hierarchical and cooperative control, energy management systems, smart metering and the internet of things for AC/DC microgrid clusters and islanded minigrids; recently specially focused on maritime microgrids for electrical ships, vessels, ferries and seaports. Prof. Guerrero is an Associate Editor for the IEEE TRANSACTIONS ON POWER ELECTRONICS, the IEEE TRANSACTIONS ON INDUSTRIAL ELECTRONICS, and the IEEE Industrial Electronics Magazine, and an Editor for the IEEE TRANSACTIONS on SMART GRID and IEEE TRANSACTIONS on ENERGY CONVERSION. He has been Guest Editor of the IEEE TRANSACTIONS ON POWER ELECTRONICS Special Issues: Power Electronics for Wind Energy Conversion and Power Electronics for Microgrids; the IEEE TRANSACTIONS ON INDUSTRIAL ELECTRONICS Special Sections: Uninterruptible Power Supplies systems, Renewable Energy Systems, Distributed Generation and Microgrids, and Industrial Applications and Implementation Issues of the Kalman Filter; the IEEE TRANSACTIONS on SMART GRID Special Issues: Smart DC Distribution Systems and Power Quality in Smart Grids; the IEEE TRANSACTIONS on ENERGY CONVERSION Special Issue on Energy Conversion in Next-generation Electric Ships. He was the chair of the Renewable Energy Systems Technical Committee of the IEEE Industrial Electronics Society. He received the best paper award of the IEEE Transactions on Energy Conversion for the period 20142015. In 2014 and 2015 he was awarded by Thomson Reuters as Highly Cited Researcher, and in 2015 he was elevated as IEEE Fellow for his contributions on "distributed power systems and microgrids." 